\begin{tabular}{|c|c|c|c|c|c|}
\hline MUNIBE Antropologia-Arkeologia & $n^{\circ} 67$ & $5-34$ & DONOSTIA & 2016 & ISSN 1132-2217 • eISSN 2172-4555 \\
\hline
\end{tabular}

\title{
El Abrigo del Carabión (San Mamés de Aras-Cantabria, España) en el contexto mesolítico del Estuario del Asón y Marismas de Santoña
}

\author{
Un depósito arqueológico con una secuencia de ocupación en el Holoceno inicial \\ y medio en el oriente de la región cantábrica
}

\section{Abrigo del Carabión (San Mamés de Aras, Cantabria, Spain) in the context of the Asón Estuary and Santoña Saltmarshes in the Mesolithic \\ An archaeological deposit with an early and middle Holocene occupation sequence in the east of the Cantabrian region}

PALABRAS CLAVES: Aziliense, Mesolítico, Región Cantábrica oriental, Paleoambiente, Estrategias económicas. GAKO-HITZAK: Aziliarra, Mesolitoa, Kantabria ekialdeko ingurua, Paleoingurumena, Estrategia ekonomikoak. KEY WORDS: Azilian, Mesolithic, eastern Cantabrian region, Palaeoenvironment, Subsistence strategies.

\section{Mercedes PÉREZ-BARTOLOMÉ(1), Pedro CASTAÑOS(2), Francisco ETXEBERRIA(3), Arturo MORALES MUÑIZ(4), Eufrasia ROSELLÓ IZQUIERDO(4), Ma José GIL GARCÍA(5), Blanca RUIZ ZAPATA ${ }^{(5)}$, Alfredo PRADA ${ }^{(6)}$, Marta SOLAR ${ }^{(7)}$ y Paloma UZQUIANO ${ }^{(8)}$}

\section{RESUMEN}

En este artículo se ofrece un avance del estudio multidisciplinar del depósito arqueológico del Abrigo del Carabión (S. Mamés de Aras, Cantabria). El yacimiento por su situación y registro arqueológico, constituye un enclave fundamental en el análisis de la transición en los modos de vida de los últimos cazadores recolectores a la economía productora en la región cantábrica. Contiene un depósito de ocupación humana que abarca desde el XI al VI milenio BP. La estratigrafía identificada contiene un primer nivel fértil (N.3) de cronología aziliense, separado por un hiato, de un segundo nivel de ocupación (N.1), formado por un conchero de especies marinas y caracol terrestre (Cepaea nemoralis) con una cronología en el Mesolítico y Neolítico inicial. Posteriormente el abrigo fue utilizado como depósito funerario.

\section{LABURPENA}

Artikulu honek Abrigo del Carabióneko (S. Mamés de Aras, Kantabria) gordailu arkeologikoan eginiko diziplina anitzeko azterlanaren aurrerapen bat eskaintzen du. Aztarnategia, duen kokalekuagatik eta erregistro arkeologikoagatik, funtsezko lekua da Kantabria inguruan azken ehiztari biltzaileek bizimodu hura aldatu eta ekoizpen-ekonomiara eginiko trantsizioa aztertzeko. Duela XI mila urtetik duela VI mila urtera arteko giza okupazioaren gordailu bat du. Identifikatutako estratigrafiak kronologia aziliarreko lehen maila emankor bat du (N.3), bigarren okupazio-mailatik (N.1) hiato baten bidez bereizia. Itsas espezieez eta lurreko barraskiloz (Cepaea nemoralis) osatutako maskortegi bat du, Mesolitoko eta hasierako Neolitoko kronologia duena. Ondoren, babeslekua, hilobi-gordailu gisa erabili zuten.

\section{ABSTRACT}

The archaeological excavation in El Carabión Rockshelter (San Mamés de Aras, Cantabria) documented a deposit formed by occupations by human groups between the eleventh and sixth millennia BP. Owing to its situation and archaeological record, this is a key site to understand the way of life of the last hunter-gatherers in the transition towards the farming economy in Cantabrian Spain.

The site was identified in the 1950s under the supervision of the Cantabrian Museum of Prehistory. However, it was not excavated until 2009. The results obtained in studies of the sedimentology, palynology, malacology, fauna, lithic assemblages and funerary deposit found at the site has led to an analysis of socioeconomic strategies adapted to environmental and climate changes in the Holocene, in a period covering the Azilian, Mesolithic and early Neolithic in the eastern Cantabrian region.

\footnotetext{
(1) Doctorado Universidad Nacional de Educación a Distancia (UNED). mercedesper@hotmail.com. Avd. de Cantabria, 21-1-4 Ctro. 39012 Santander.

(2) Sociedad de Ciencias Aranzadi. Centro Geo-Q, Santimami Auzoa, E-48940 Leioa, España. pedrocastanos@yahoo.es

(3) Facultad de Medicina. Universidad del País Vasco. (UPV-EHU)- SC Aranzadi.

(4) Laboratorio de Arqueozoología. Depto. Biología Universidad Autónoma de Madrid.

(5) Área de Paleontología. Universidad de Alcalá de Henares.

(6) Restaurador, conservador Ministerio de Educación Cultura y Deporte. Cantabria.

(7) Licenciada en Ciencias Geológicas. Profesora de enseñanzas medias de la Consejería de Educación del Gobierno de Cantabria.

(8) Universidad Nacional de Educación a Distancia (UNED).
} 
These environmental changes and the new resources available to the human groups are correlated to the techno-cultural responses observed in the evidence of the archaeological remains. These observations, supported by radiocarbon determinations, enable a definition of the chrono-cultural sequence of the last hunter-gatherers and the transition to the farming economy in Cantabrian Spain.

Abrigo del Carabión, located on the coastal plain, in an environment with abundant freshwater and close to the Asón Estuary and Santoña Saltmarshes, enjoyed access to a wide range of resources in the different fluvial, estuary and forest biotopes in the vicinity of the site. As a result, it was occupied discontinuously for about four millennia, when it specialised in hunting red deer.

\section{1.- INTRODUCCIÓN}

La intervención arqueológica en el Abrigo del Carabión se ha efectuado de urgencia en el año 2009, debido a las periódicas inundaciones que sufre la cavidad. El fuerte impacto que ejerce la crecida y circulación violenta del agua sobre el abrigo, ha producido la destrucción de gran parte del yacimiento por remoción y arrastre del contenido arqueológico.

El Carabión fue reconocido en la segunda mitad de los años 50 del pasado siglo por el Equipo de Camineros de la Diputación Provincial de Santander, dirigido por el ingeniero, GARCÍA LORENZO, bajo la supervisión del Museo Provincial de Prehistoria, dirigido por CARBALLO. El equipo efectuó un sondeo en la zona central del abrigo, en el que se identificó el yacimiento de conchero, sin embargo, estos trabajos han permanecido inéditos.

El yacimiento ha sido documentado por MUÑOZ FERNÁNDEZ (1997, inédito) y por RUIZ COBO et al (2009) en la monografía La Prehistoria del Bajo Asón.

En el año 2007 se hizo la primera datación 14C AMS en el nivel de conchero (Pérez-Bartolomé, 2016).

\section{EL CONTEXTO GEOGRÁFICO-GEOLÓGICO}

La cueva y el abrigo del Carabión forman una unidad hipogea situada en la margen izquierda del río Clarón, inmediata al puente que da acceso a S. Mamés de Aras. Las cavidades se han formado sobre materiales cretácicos urgonianos del Aptiense-Albiense Inferior, formado por calizas con Ruditas y Orbitolinas propia de los arrecifes coralinos fosilizados.

El territorio es un valle aluvial recorrido por abundantes cursos de agua, siendo los principales el río Clarón, que se une al Clarín aguas abajo de la cavidad formando la ría de Rada. La fusión de esta ría con la de Limpias da lugar a la ría de Treto que se integra en el conjunto del estuario del Asón y las Marismas de Santoña.

Los procesos cársticos han dado lugar a un valle formado por laderas escarpadas, pero de escasa altura y un fondo de valle muy irregular debido al afloramiento disperso del sustrato calcáreo. Respecto al curso del río en este tramo, está desplazado hacia la margen izquierda de la llanura aluvial, ligeramente encajado por un afloramiento calizo. Se ha podido identificar un paleocauce desplazado unos 80m hacia el este, con una concavidad en planta opuesta a la que dibuja el cauce actual, este elemento morfológico, nos informa sobre el anterior trazado del río.

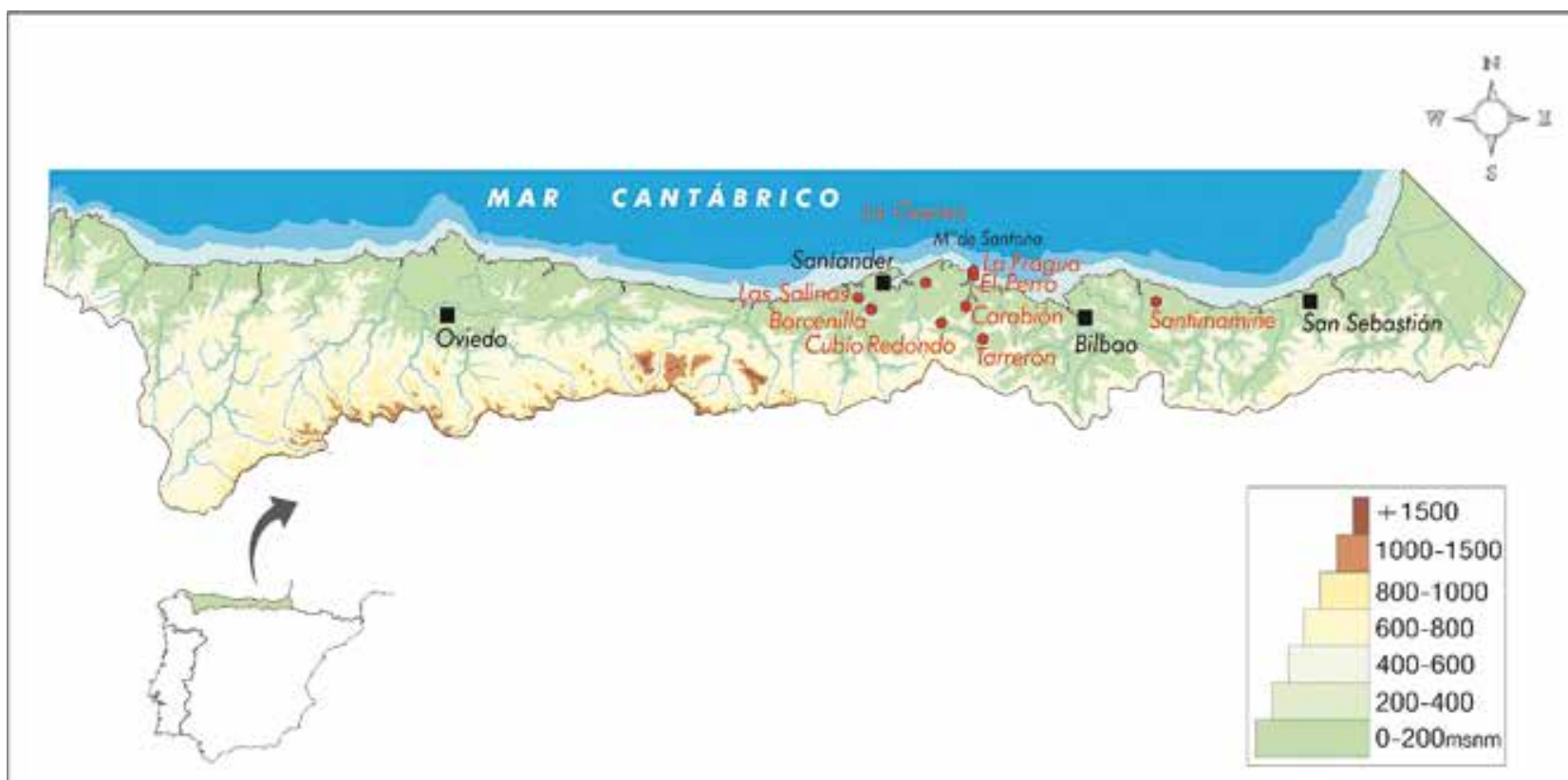

Fig. 1. Situación geográfica del Abrigo del Carabión y yacimientos mesolíticos en el centro-oriental de Cantabria. / Geographic location of Carabión Rockshelter and Mesolithic sites in central-eastern Cantabria. 


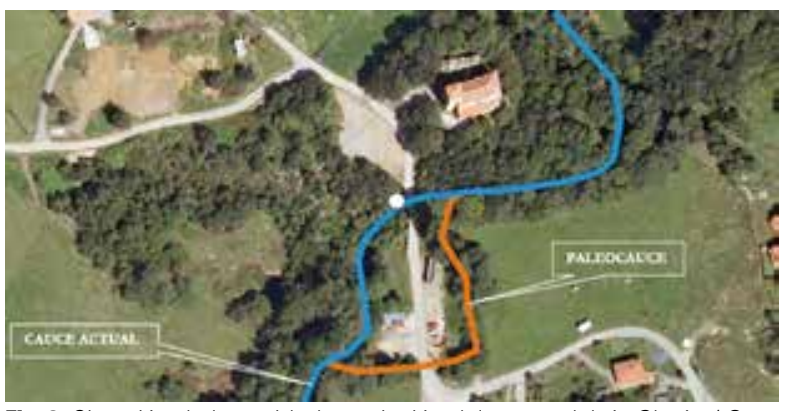

Fig. 2. Situación de la cavidad y variación del cauce del río Clarón / Geographic location of Carabión Rockshelter and Mesolithic sites in central-eastern Cantabria.

\section{LOCALIZACIÓN Y DESCRIPCIÓN DEL ASENTA- MIENTO}

El Abrigo del Carabión se encuentra en San Mamés de Aras (Cantabria) en el centro oriental de la Cornisa Cantábrica. Coordenadas ED50. X: 458.990; Y: 4.800.730; Z: 15 m snm. (Hoja 36 III MTNE). Se sitúa en la llanura litoral, a una distancia inferior a $2 \mathrm{~km}$ de la Ría de Rada y a 7, $5 \mathrm{~km}$ de las Marismas de Santoña.

La cavidad abre orientada al SE en la base de un pequeño macizo calizo emergente. El asentamiento está formado por el abrigo, excavado por el río en la base del macizo calizo, muy próximo al cauce y la cueva anexa. La planta del abrigo tiene forma de arco con un pequeño covacho en el extremo oeste, donde se colapsa por derrumbe de la visera. Presenta actualmente un desarrollo en longitud de $10 \mathrm{~m}$ con una profundidad de $1 \mathrm{~m}$ en el extremo oeste y $6 \mathrm{~m}$ en la parte más profunda. El perfil calizo continúa hacia el oeste, si bien se ha producido el derrumbe de parte del frente calizo, bajo el que se conserva yacimiento. Pasado el derrumbe se accede a la cueva, que también ha sufrido un colapso de la parte exterior y del vestíbulo. La cueva forma una galería rectilínea de $30 \mathrm{~m}$ de longitud que en el fondo se estrecha y se colmata. El conjunto dista del

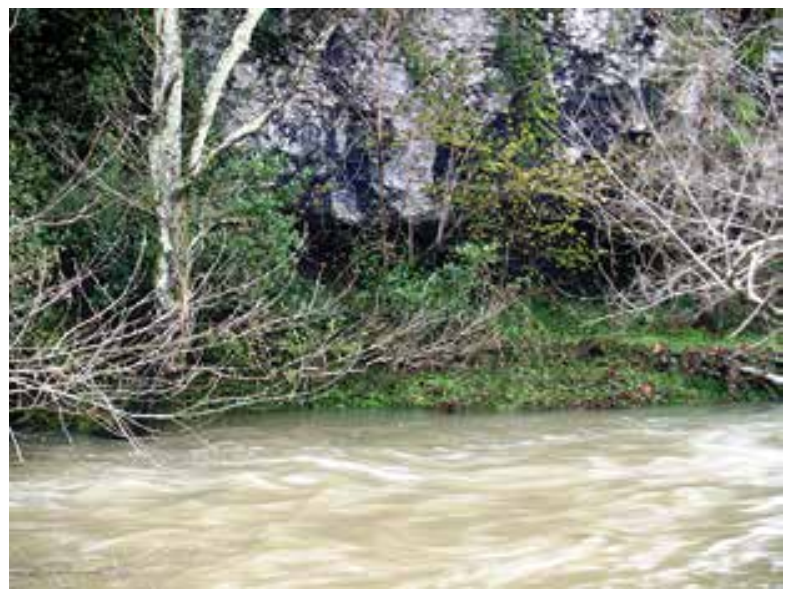

Fig. 3. Situación de la cavidad en la margen izquierda del río Clarón / Situation of the site on the left bank of the river Clarón. cauce unos 5 a $6 \mathrm{~m}$, con un desnivel inferior a $1 \mathrm{~m}$ en el abrigo y superior en la cueva. La plataforma sobre la que se asienta el abrigo se compone de arenas y arcillas depositadas por el río.

\section{EL YACIMIENTO}

El yacimiento se extiende, a modo de banco a lo largo del abrigo, con un ligero buzamiento hacia la parte central, y en el cubículo bajo el derrumbe en la zona oeste. La secuencia estratigráfica obtenida en el cuadro C-5, con una profundidad de $115 \mathrm{~cm}$, sin alcanzar el nivel de base, ha proporcionado cinco niveles que se repiten a lo largo de todo el yacimiento. Los niveles fértiles son el N3, que corresponde a una primera ocupación en el Aziliense y el N1, de cronología mesolítica y de transición al Neolítico inicial, ambos separados por un hiato estéril.

En el fondo oeste del abrigo, en el cuadro 11 se han recuperado varios fragmentos de cráneo humano, correspondiente a una inhumación en el interior del conchero.

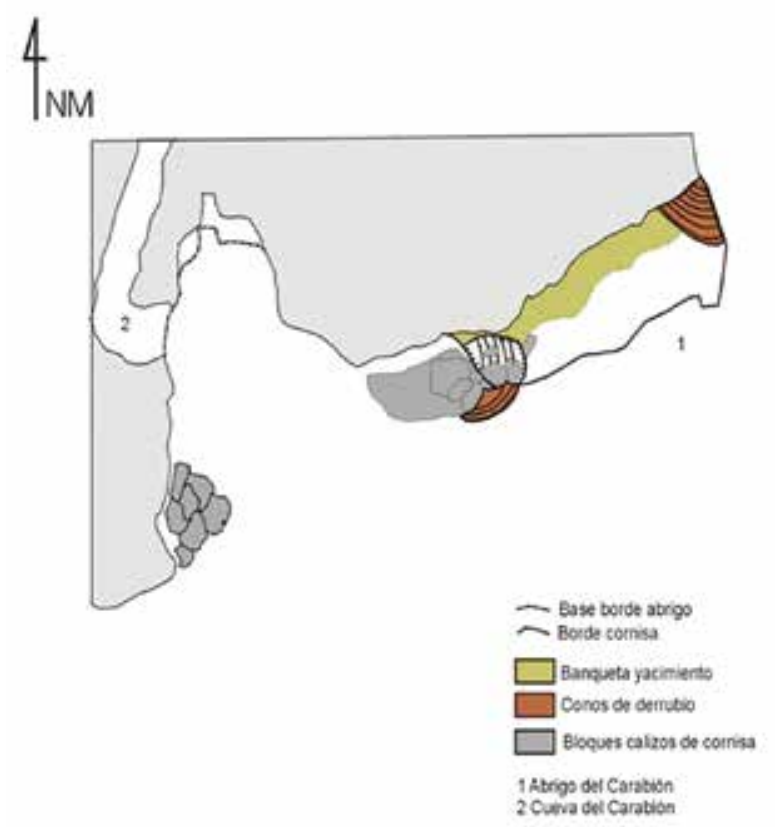

Fig. 4. Croquis del hábitat: cueva y abrigo del Carabión / Sketch of the habitat: Carabión Cave and Rockshelter.

\section{LA EXCAVACIÓN ARQUEOLÓGICA}

La intervención arqueológica se ha planteado, dado el estado vulnerable en que se encuentra el yacimiento, con los objetivos de obtener información sobre el depósito, y especialmente, de su conservación. Así el plan de actuación se ha dirigido a la recuperación de los materiales que se encontraban en las áreas más expuestas y alteradas, interviniendo en la parte central (cuadros C5, D5) y en el extremo oeste (cuadro 
G2) donde se encontraba desmantelado el nivel 1 y los restos aparecían en superficie. En conjunto el área excavada supone en torno a $1 \mathrm{~m}^{2}$.

Se siguió el protocolo de toda excavación arqueológica, señalando la cuadrícula con números y letras y subdividiendo cada cuadro en sectores de $33 \mathrm{~cm}$. El levantamiento de la masa del depósito se realizó en tallas de $5 \mathrm{~cm}$ de espesor, con el método de coordenadas cartesianas y control tridimensional de las evidencias arqueológicas (LAPLACE, G.; MEROC, L. 1954, 1956. LAPLACE, G. 1971, MORA TORCAL, R. et al, 2014).

En el cuadro C5 se excavaron los sectores uno al seis de forma parcial, ya que se encontraban muy erosionados. En el cuadro D5 los sectores (3-6) de con-

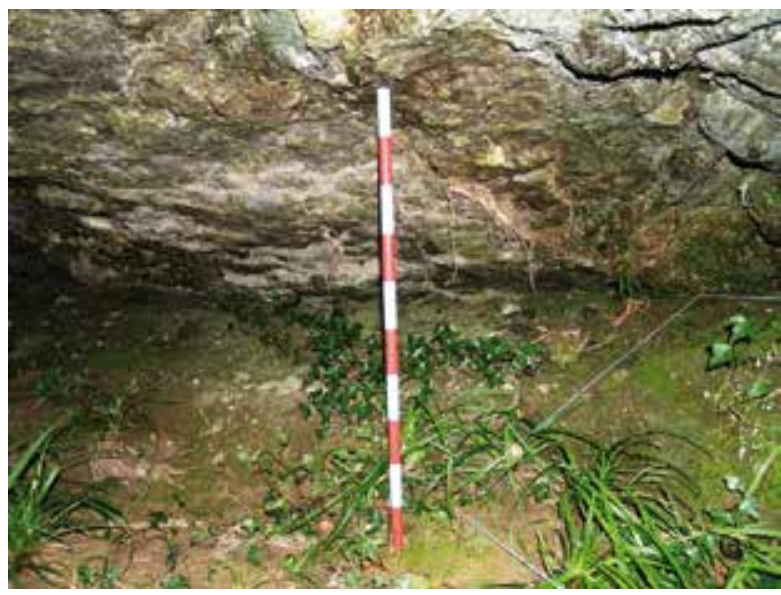

Fig. 5. Situación del yacimiento previo a la intervención / Situation of the deposit prior to the excavation.
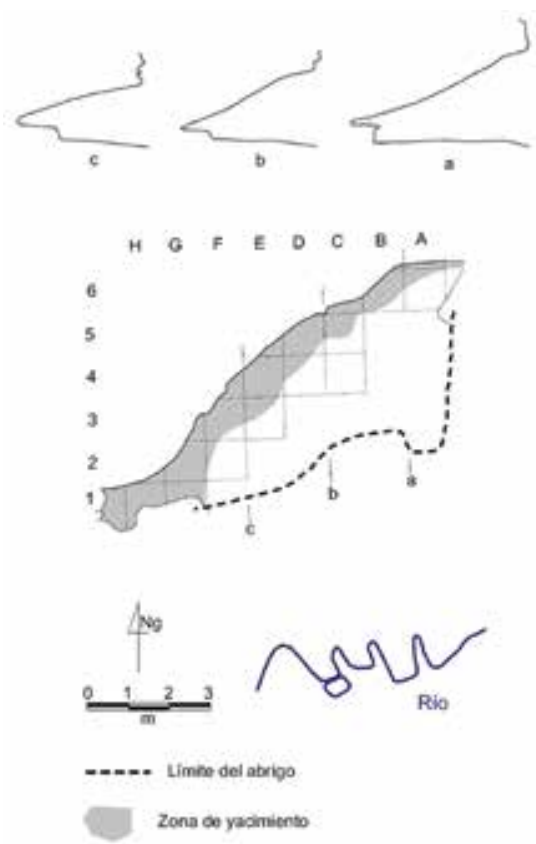

Abrigo de Carabión, Voto, 2009
Fig. 6. Plano topográfico del A. de phic plan of Carabión Rockshelter. Carabión / Topogra- tacto con C5 y profundidad $58 \mathrm{~cm}$. En el G2 se recuperaron abundantes restos de fauna en superficie y se excavaron de forma parcial los sectores dos al nueve con una profundidad de $30 \mathrm{~cm}$, con el fin de alcanzar el nivel inferior aziliense en estratigrafía.

Durante el proceso de excavación se tomaron muestras para análisis de Sedimentología, Palinología, Antracología y dataciones 14C AMS.

El sedimento se recuperó de forma total para ser procesado en el laboratorio del Centro de Investigación de Altamira, donde se procedió a la flotación de todo el sedimento y posterior lavado sobre dos cribas de 3 y $1 \mathrm{~mm}$ de luz de malla. El triado posterior de los restos se ha efectuado con lupa bifocal.

\subsection{Secuencia estratigráfica y cultural}

El cuadro que ofrece información más completa es el C5, donde se ha alcanzado la mayor profundidad (115 cm en el Sector 1), con el fin de identificar la estratigrafía completa del depósito. No se ha llegado al nivel de base, debido a la dificultad que ofrecía el reducido espacio de excavación.

El estudio sedimentológico (SOLAR), confirma los 5 niveles obtenidos en la secuencia arqueológica.

Nivel 0. Costra calcárea de potencia irregular, oscilando entre 8 a $10 \mathrm{~cm}$ cuyo espesor adelgaza hacia el exterior del abrigo y se engrosa hacia los extremos y base de la pared interna de la cavidad. En las superficies donde no existe esta costra calcárea se identifica un nivel orgánico húmico evolucionado que no supera los $5 \mathrm{~cm}$ de espesor.

Nivel 1. Subdividido en:

1.1. Conchero en sustrato de limos y arcillas cuya potencia es de $5 \mathrm{~cm}$. y que contiene restos de malacología marina.

1.2. Conchero en sustrato de limos y arcillas con una potencia de $35 \mathrm{~cm}$. Formado por una matriz de limos con elevado contenido en materia orgánica que aporta un color marrón oscuro al suelo, procedente del lavado del horizonte superior. Destaca el contenido en elementos gruesos constituidos por cantos calcáreos, angulosos y subangulosos, con morfología aplanada en forma de escamas y vértices redondeados que forman el esqueleto. Están mezclados con abundantes bioclastos (conchas de ostreidos, huesos, caparazones de caracoles, etc.) y fragmentos de coladas calcáreas fracturadas. El límite con los niveles superior e inferior es neto en los lugares donde se halla truncado por la costra calcárea superior y ligeramente transicional en el resto de contactos. El espesor es variable de unos puntos a otros dado que el plano de contacto superior es irregular, mostrando un cierto paleorrelieve. En este nivel no se identifican estructuras sedimentarias de orientación ni clastos que pudieran relacionarlo con un depósito fluvial. Los elementos gruesos forma- 
D5

C5

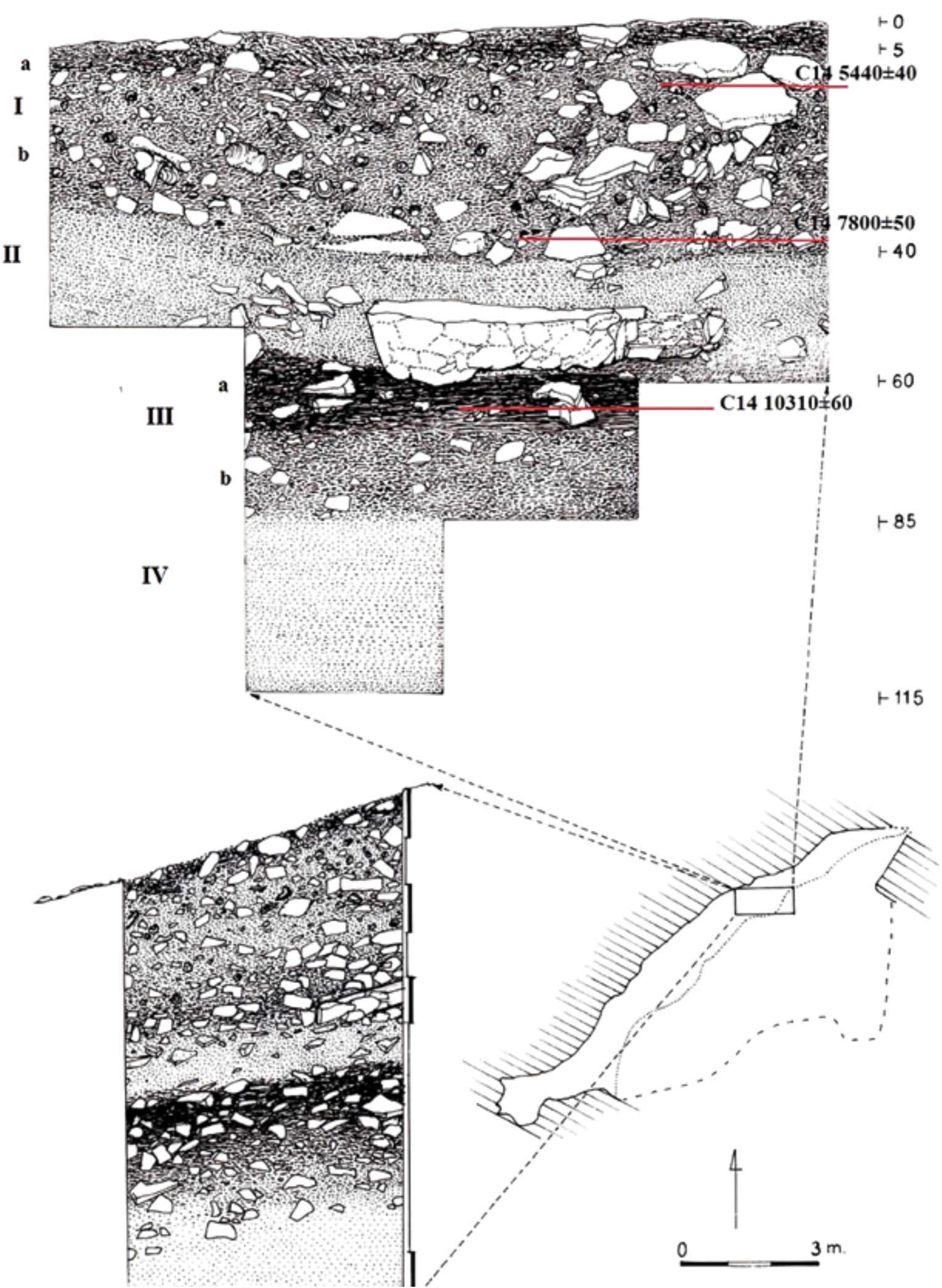

Fig. 7. Planos y Corte estratigráfico Abrigo del Carabión cuadros C5-D5 / Plan and section of Squares C5-D5 in Carabión Rockshelter. 
dos por cantos de caliza proceden de los procesos de alteración del techo de la cavidad. Es un nivel arqueológicamente muy fértil cuya continuidad lateral se ve truncada por un nivel erosivo actual. En este nivel se han obtenido dos dataciones 14C AMS atribuidas culturalmente al Mesolítico y transición al Neolítico.

Nivel 2. Se trata de un nivel continuo y uniforme, identificado en todas las catas realizadas, cuyo espesor oscila entre 15 y $20 \mathrm{~cm}$. A muro se identifica un bloque tipo laja de unos $40 \mathrm{~cm}$ de longitud y $10 \mathrm{~cm}$ de altura correspondiente a un trozo de estrato calizo desprendido del techo de la cavidad.

En cuanto a su composición, este nivel se diferencia del superior en que es un suelo arcilloso, que posee menor cantidad de materia orgánica y menor proporción de elementos gruesos. La mayor proporción de arcillas y elementos finos frente a los gruesos, así como una mayor proporción de agregados calcíticos indica unas condiciones de mayor humedad y, de aportes externos de coladas de barro limos y arcillas. Arqueológicamente es estéril.

Nivel 3. Nivel de color rojizo con un espesor uniforme de unos $25 \mathrm{~cm}$. Formado por un esqueleto de elementos gruesos clastosoportados cuya proporción representa la mayor parte del depósito (60\%), angulosos a muy angulosos. La naturaleza de los cantos es predominantemente caliza, con morfología escamada aunque también se identifican bioclastos alóctonos asociados a la actividad humana (conchas de moluscos, huesos y carbones). La textura es suelta y pedregosa en el esqueleto, mientras que la matriz es bastante arcillosa, plástica y adherente, con estructura granulosa.

Los vértices de los clastos del esqueleto apenas están redondeados lo que indica un bajo grado de alteración química. También están ausentes los fragmentos de coladas de calcita por lo que el depósito se corresponde con un periodo en el que los procesos de precipitación química eran poco representativos. Es el primer nivel arqueológicamente fértil y está datado en el Aziliense.

\section{Nivel 4.}

Nivel de limos arcillosos de color ocre característico claramente diferenciado de los niveles superiores cuya potencia es desconocida porque la cata realizada no ha alcanzado el contacto con un nivel inferior. El contacto del techo con el nivel 3 es regular y neto. Este nivel carece totalmente de agregados húmicos y es arqueológicamente estéril. Su potencia $25 \mathrm{~cm}$ sin alcanzar el nivel de base debido a la escasa superficie excavada en este nivel.

\section{DATACIONES RADIOCARBÓNICAS}

Se ha efectuado una selección de muestras para análisis 14C AMS analizadas en Poznan Radiocarbon Laboratory. En la Tabla 5 se presentan los resultados obtenidos en años sin calibrar y calibrados con la curva CalPal Hulu 2007 (Weninger et Joris, 2007).

La cronología nos informa del inicio de la ocupación de la cavidad por los grupos humanos en el nivel 3 , datado en $10310 \pm 60$ BP, con atribución cultural en el Aziliense, y se prolonga a lo largo de más de cuatro milenios. Se registra un abandono entre $\mathrm{X}$-IX milenios (hiato identificado en todo el depósito), probablemente debido a causas climatológicas que alteraron las condiciones de habitabilidad de la cavidad. Este hiato en la ocupación se ha constatado también en el vecino yacimiento de La Fragua (Santoña) entre el 9.6 ka BP y 7,5 ka BP (MARÍN, 2004: 34). La cavidad vuelve a ser ocupada en un momento avanzado del Mesolítico en torno a 7,8 ka BP, se prolonga hasta 5,7 ka BP, y posteriormente es utilizada como depósito funerario hacia el 5,4 ka BP.

Lafecha de ocupación en el Aziliense(10310ะ60BP), es contemporánea con las obtenidas en yacimientos de Cantabria: El Castillo N.6 (10310 $\pm 120 B P)$ (SOTO BARREIROS, 2003:188); Piélago II N. 1 (10280 120 BP) (SOTO BARREIROS, 2003). En el País Vasco: Arenaza

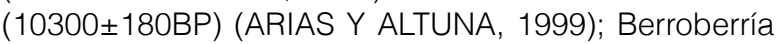
D Sup. (10300 $\pm 170 B P)$ (BARANDIARÁN, I. 1990); Laminak II NI (10380 $\pm 140 B P)$ (BERGANZA Y ARRIBAS, 1994); Portugain (10370 \pm 90 BP) (BARANDIARÁN; CAVA, 1986); URRATXSA III (10240 \pm 100 BP) (MUÑOZ; BERGANZA, 1997).

La fecha de 7,8 ka BP obtenida en el nivel Mesolítico del Carabión es bastante próxima a las de Mazaculos II (Asturias) (7840 \pm 40BP) (DRAK y GARRALDA, 2009); Toralete (Asturias) (7890 \pm 80 BP) (FANO, 2007),

\begin{tabular}{|c|c|c|c|c|c|c|c|}
\hline \multicolumn{2}{|c|}{ Procedencia } & Material & R. Laborat. & BP & Cal. BP 20 & Cal. BC $2 \sigma$ & Método \\
\hline C-5 & $\begin{array}{c}N 1 \\
Z:-20 \mathrm{~cm}\end{array}$ & Carbón & Poz-18732 & $5750 \pm 40$ & $6561 \pm 57$ & $4710-4490$ & C14 AMS \\
\hline C-5 & $\begin{array}{c}N 1 \\
Z:-40 \mathrm{~cm}\end{array}$ & Hueso & Poz-32691 & $7800 \pm 50$ & $8576 \pm 52$ & $6770-6480$ & C14 AMS \\
\hline C-5 & $\begin{array}{c}\text { N3 } \\
\text { Z: }-72 \mathrm{~cm}\end{array}$ & Hueso & Poz-30594 & $10310 \pm 60$ & $12187 \pm 196$ & $10450-9850$ & C14 AMS \\
\hline $\mid-1$ & $\begin{array}{c}N 1 \\
Z:-10 \mathrm{~cm}\end{array}$ & Hueso humano & Poz-30592 & $5440 \pm 40$ & $6251 \pm 34$ & $4360-4230$ & C14 AMS \\
\hline
\end{tabular}

Tabla 1: Dataciones radiocarbónicas calibradas con la curva CalPal Hulu 2007 (Weninger et Joris, 2007) / Radiocarbon dates calibrated with the CalPal Hulu 2007 curve (Weninger and Joris, 2007). 
J3 (País Vasco) (7780 $\pm 130 B P ; 7770 \pm 50$ BP) (IRIARTE et al, 2005); La Garma (Cantabria) (7710 \pm 90 BP) (ARIAS et al, 2000).

La datación obtenida en la parte superior del conchero (N1 -20 cm), 5780 $\pm 50 \mathrm{BP}$, es considerada en la región cantábrica como Neolítico inicial, en el que ya se han implantado algunos de los factores de la economía productiva.

El depósito funerario del Carabión, datado en 5,44 ka BP, parece situarse en un momento neolítico en el que es frecuente la inhumación en cuevas, práctica funeraria que perdura hasta que se generalizan los enterramientos colectivos con la introducción del fenómeno megalítico, fecha que se sitúa en segunda mitad del $\checkmark$ milenio BP $(\approx 4550$ cal. BC) (DIEZ CASTILLO, 2010).

\section{PALEOVEGETACIÓN}

Los estudios polínicos (RUIZ ZAPATA; GIL GARCíA), se han llevado a cabo sobre nueve muestras procedentes del Cuadro C-5, Sector 1, localizadas junto al muro, casi en el centro del abrigo, en una profundidad de 90 cm. La extracción del polen, se realizó de acuerdo con los protocolos estándar (COÛTEAUX, 1977). Los taxones identificados se expresan porcentualmente, en el Histograma polínico detallado (Fig.8), realizado con los programas TILIA® y TILIA GRAPH $®$ (@) ERIC C. GRIMM, 1987, 2004), sobre un total de más de 300 granos en cada muestra.

Los resultados más relevantes, se presentan resumidos en la Tabla II, y en el Diagrama sintético (Fig.9), realizado a partir de la agrupación de taxones, que comparten afinidades ecológicas. Dichas agrupaciones (bosque local, ruderales, pastizales y nitrófilas y los MNP secos), se comparan con el comportamiento de los taxones con mayor desarrollo a lo largo de la secuencia (Pinus y Chenopodiaceae). A nivel polínico, no se detectan claros indicadores de cultivos en el área, sin embargo el comportamiento de Apiaceae, Brassicaceae y Fabaceae, Familias en cuyo seno se desarrollan elementos comestibles, nos ha llevado a agruparlos bajo el epígrafe PIE (taxones potencialmente de interés económico, fruto de un posible cultivo). Los resultados se presentan resumidos en la Tabla II y en los histogramas (Fig.8-9).

\begin{tabular}{|c|c|}
\hline \multicolumn{2}{|c|}{ POLEN/VEGETACIÓN - CLIMA/ACTIVIDAD ANTRÓPICA } \\
\hline $\begin{array}{r}\text { Abrigo de Carabión (San Mamés de Aras-Voto, Car } \\
27 \text { taxones (6 son arbóreos, } 3 \text { arbustivos y } 18 \text { herbáceos), esporas monoletas y t }\end{array}$ & $\begin{array}{l}\text { oria (CAR) } \\
\text { tas y } 16 \text { Microfósiles no Polínicos (MNP). }\end{array}$ \\
\hline 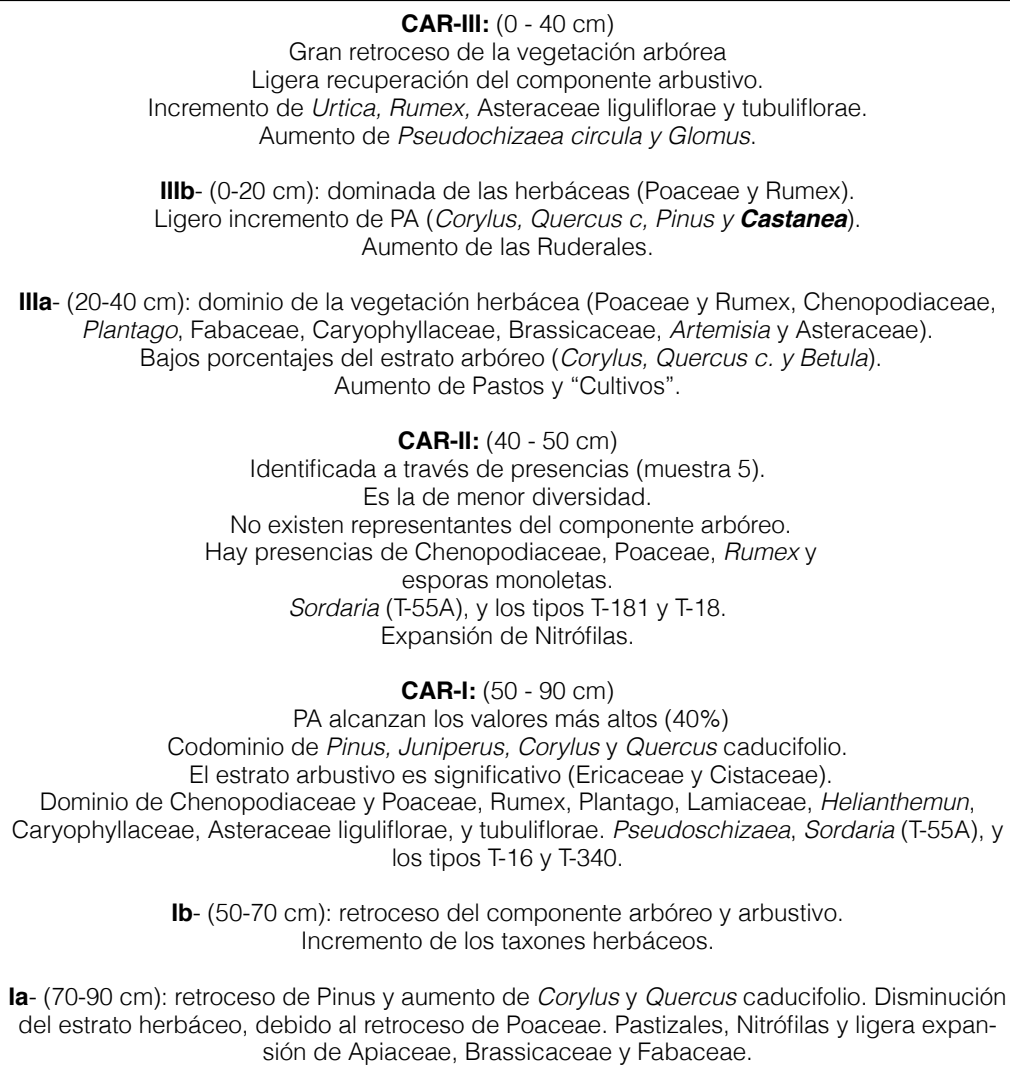 & $\begin{array}{l}\text { Suelos relativamente secos y nitrificados } \\
\text { II- Condiciones secas. } \\
\text { Agua puntual produciendo lavado del sedimento. } \\
\text { Presencia de fauna local. } \\
\text { I- Condiciones algo templadas y húmedas } \\
\text { Inicios del uso del territorio }\end{array}$ \\
\hline
\end{tabular}

Tabla 2: Descripción del contenido polínico del perfil CAR / Description of the pollen contents in the CAR section. 


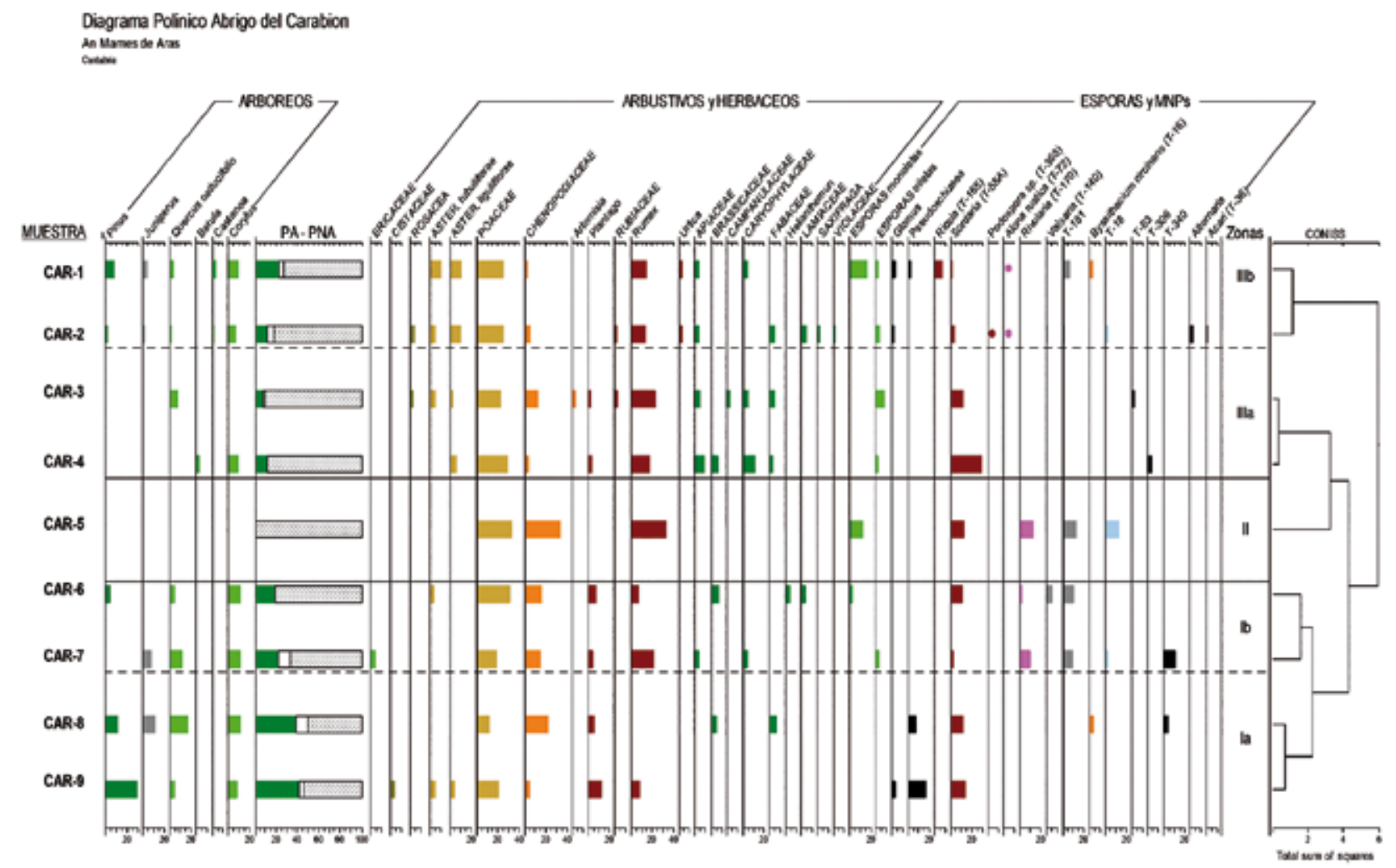

Fig. 8. Histograma Polínico detallado de la secuencia CAR. Los porcentajes de los taxones arbóreos (A), arbustivos (B) y herbáceos (B) se han calculado sobre la suma base $(A+B+C)$. Los porcentajes de las esporas $(D)$ y de los MNP $(E)$, sobre la suma total $(A+B+C+D+E) / D e t a i l e d$ pollen histogram of the $C A R$ sequence. The percentages of arboreal taxa $(A)$, shrubs $(B)$ and grasses $(C)$ have been calculated over the sum of $A+B+C$. The percentages of spores (D), and NNP $(E)$, over the total sum of $A+B+C+D+E$.

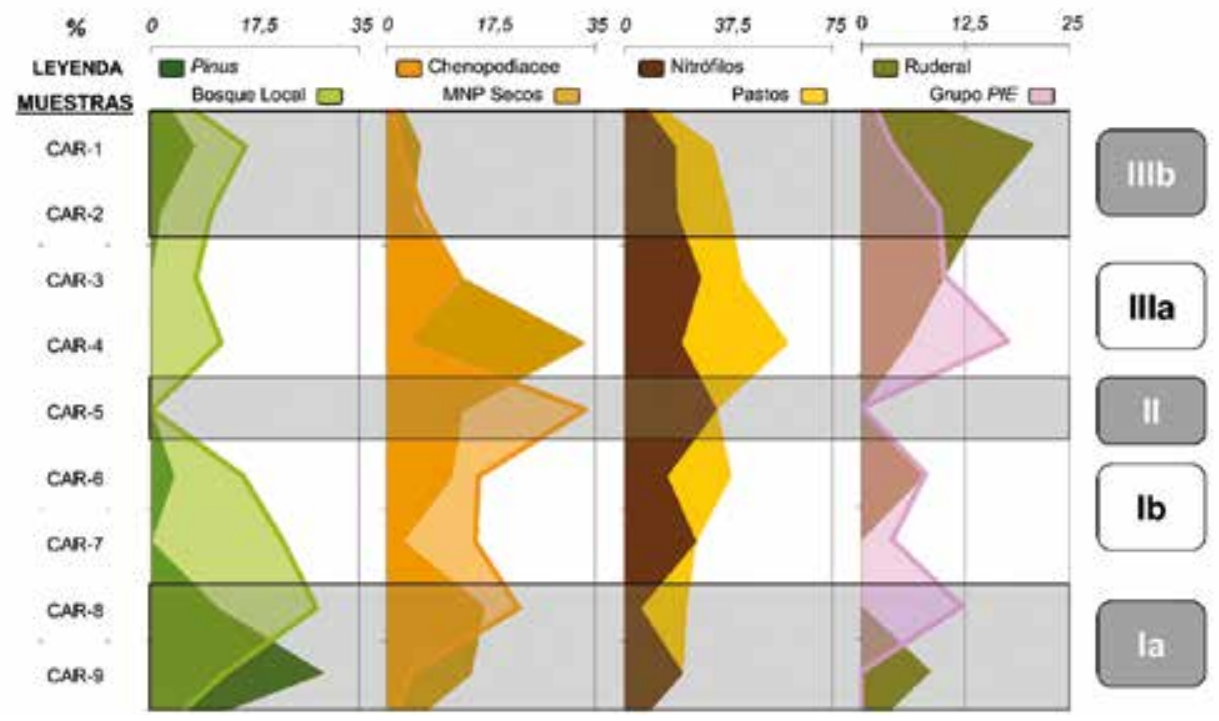

Fig. 9. Representación sintética de los elementos más significativos de la secuencia CAR. Se han representado una selección de taxones o grupos, con el fin de comparar las distintas zonas del registro. La curva de Bosque local está compuesta por Betula, Castanea, Corylus y Quercus caducifolio. La curva de MNP secos por Sordaria, Byssitheci, Podospora y T-306. La curva de Nitrófilos por Plantago, Rumex, Rubiaceae y Urtica. La curva de Pastos por Apiaceae, Brassicaceae, Campanulaceae, Caryophyllaceae, Fabaceae, Poaceae y Rosaceae. La curva de Ruderal por Artemisia, Asteraceae liguliflorae y tubuliflorae. El grupo PIE, esta formada por aquellos taxones herbáceos, que aún formando parte del paisaje natural (Apiaceae, Brassicaceae y Fabaceae), se trata de familias que poseen taxones de interés alimenticio / Summary of the most significant elements in the CAR sequence. Samples of taxa and groups have been represented in order to compare the different zones in the record. The local woodland curve is formed by Betula, Castanea, Corylus and deciduous Quercus. The dry NNP curve by Sordaria, Byssitheci, Podospora and T-306. The nitrophile curve by Apiaceae, Brassicaceae, Campanulaceae, Caryophyllaceae, Fabaceae, Poaceae and Rosaceae. The grassland curve by Apiaceae, Brassicaceae, Campanulaceae, Caryophyllaceae, Fabaceae, Poaceae and Rosaceae. The ruderal curve by Artemisia. Asteraceae liguliflorae and tubuliflorae. The PIE group is formed by herbaceous taxa that, while forming part of the natural vegetation (Apiaceae, Brassicaceae and Fabaceae), belong to families with taxa of alimentary interest. 


\section{ANTRACOLOGÍA}

El análisis de los restos carbonizados (maderas) recuperados en el abrigo del Carabión se ha efectuado sobre 34 muestras obtenidas por flotación del sedimento y recogidas en estratigrafía en los cuadros C5-D5.

A) La flora aziliense se caracteriza por la presencia de taxones pioneros como el Abedul (Betula sp.) que es dominante, el Sauce (Salix sp), el espino amarillo (Hippophae rhamnoides), pero también por la presencia puntual de taxones mesófilos como los robles caducifolios (Quercus) cuya extensión es característica del inicio del Holoceno. No obstante la presencia de robles caducifolios junto a la de otros taxones mesófilos como el avellano, el fresno o el haya (Corylus avellana, Fraxinus excelsior, Fagus sylvatica) también presentes en el abrigo del Carabión, ha sido atestiguada en el cantábrico a nivel antracológico desde momentos anteriores al Holoceno (UZQUIANO, 1992 a, 1992 b, 1995, 1998). La dinámica de vegetación en este yacimiento hacia $10.3 \mathrm{Ka} \mathrm{BP}$, se caracteriza por el codominio de Betula-Quercus caducifolios. Esta misma dinámica está presente en otras ocupaciones azilienses más o menos contemporáneas y próximas como el Abrigo de la Peña del Perro (10.1 Ka BP) situado en la Bahía de Santoña.

B) Los resultados obtenidos en las ocupaciones del Mesolítico están subdivididos en dos momentos a tenor de las dataciones obtenidas y de las fluctuaciones observadas a nivel florístico a partir de los dos taxones principales Betula y Quercus.

- Hacia 7.8 Ka BP taxones colonizadores como el Abedul ceden en favor de los robles caducifolios. Asistimos a la extensión del bosque caducifolio característico de estas latitudes con la presencia discreta de encinas (Quercus ilex).

- Hacia 5.8 Ka BP, los resultados son algo más informativos que en la etapa precedente. El bosque caducifolio es la formación dominante en esta zona caracterizado por el dominio de los robles caducifolios junto a otros taxones mesófilos como avellanos y fresnos. El encinar cantábrico costero parece confirmarse a partir de la presencia de encinas (Quercus ilex) cuyos valores a pesar de ser algo superiores a los registrados en la etapa precedente, siguen siendo discretos, y por la presencia de madroños (Arbutus unedo), arbusto que suele aparecer asociado a la encina teniendo en cuenta los datos biogeográficos actuales (CENDRERO et al., 1986).

La extensión del bosque caducifolio, así como la presencia del encinar cantábrico, serían las características florísticas más sobresalientes de estos momentos del Holoceno inicial-medio, según los resultados antracológicos obtenidos. Estos mismos datos florísticos han sido puestos de manifiesto en otros yacimientos de la zona, como las Cuevas de Mazaculos y La Llana situadas en el litoral este asturiano (UZQUIANO, 1992 a, 1995). Los grupos humanos que ocuparon este abrigo explotaron todos estos recursos leñosos adaptando sus estrategias de recolección de leña a los cambios de vegetación según la dinámica observada en el análisis antracológico.

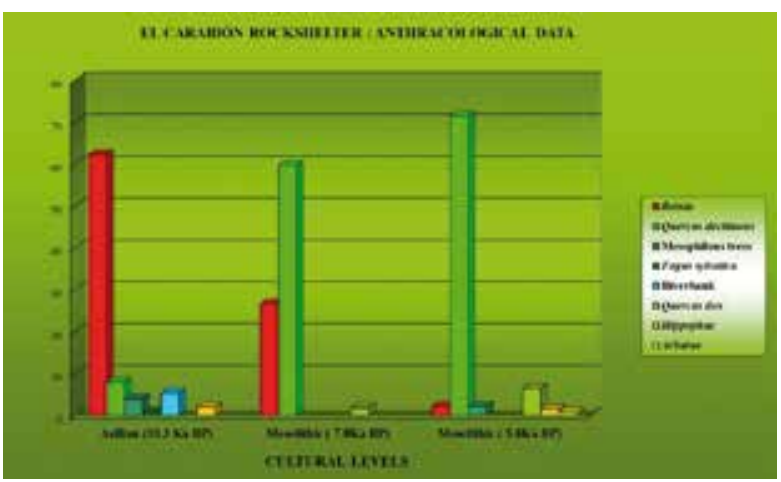

Fig. 10. Frecuencias del estudio antracológico del Abrigo del Carabión (Uzquiano, P. 2009) / Frequencies of the anthracological study at Carabión Rockshelter (Uzquiano, P. 2009).

\section{ESTRATEGIAS ECONÓMICAS: LA FAUNA}

Diferenciando los dos niveles fértiles N3 y N1, se observan variaciones en la utilización y disponibilidad de los recursos.

\subsection{Macrofauna}

La muestra ósea recuperada en El Carabión alcanza un total de 4.959 fragmentos óseos cuya distribución entre los dos niveles fértiles es muy desigual. La mayor aportación (75,3\%) procede del nivel 1 al que sigue a mucha distancia el nivel 3 que sólo representa la cuarta parte del total de la muestra (24,7\%) (Tabla III).

La mayor parte de los huesos presentan un alto grado de fragmentación, razón por la cual sólo 602 $(12,14 \%)$ han sido susceptibles de identificación anatómica y taxonómica. El elevado número de fragmentos recuperados y el pequeño tamaño de la mayor parte de los mismos son indicadores de la calidad del proceso de excavación. El peso medio de los restos identificados $(7,65 \mathrm{~g})$ indica que son, como cabía esperar, más grandes que los indeterminados $(0,7 \mathrm{~g})$ tal como indican las diferencias significativas de sus pesos medios.

A excepción de las piezas dentarias que en su mayor parte se conservan enteras, la mayoría de los especímenes son fragmentos de diáfisis y epífisis de huesos largos. La ausencia de "cilindros" en los fragmentos de diáfisis y las evidencias de percusión en los propios huesos indican que la mayor parte de la fauna es de origen antrópico.

Se han identificado un total de 10 especies distintas de mamíferos: seis ungulados (uro, cabra montesa, rebeco, ciervo, corzo y jabalí) y cuatro carnívoros (oso pardo, zorro, lince y tejón). Se completa la muestra con dos restos de avifauna. El reparto en los distintos niveles es muy desigual. Además de una mayor riqueza cuantitativa de restos, el nivel 1 ofrece también una 


\begin{tabular}{|c|c|c|c|c|c|c|c|}
\hline \multicolumn{8}{|c|}{ Fauna Abrigo del Carabión } \\
\hline & \multicolumn{3}{|c|}{ Nivel 1} & \multicolumn{3}{|c|}{ Nivel 3} & \multirow{2}{*}{$\begin{array}{c}\text { Total } \\
\text { NR }\end{array}$} \\
\hline Ungulados & NR & NMI & w & NR & NMI & w & \\
\hline Bos primigenius & 4 & 1 & 70 & 1 & 1 & 58 & 5 \\
\hline Caprap. & 2 & 1 & 3 & 7 & 2 & 14 & 9 \\
\hline Rupicapra r. & 5 & 1 & 8 & & & & 5 \\
\hline Cervus e. & 350 & 13 & 3296 & 122 & 5 & 841 & 472 \\
\hline Capreolus c. & 31 & 3 & 107 & 3 & 1 & 1 & 34 \\
\hline Sus $s$. & 25 & 2 & 105 & & & & 25 \\
\hline Herbivoro pequeño & 41 & & 98 & 1 & & 5 & 42 \\
\hline Ursus a. & 2 & 1 & & & & & 2 \\
\hline \multicolumn{8}{|l|}{ Carnívoros } \\
\hline Vulpes $v$. & 1 & 1 & & & & & 1 \\
\hline Lynx sp. & 1 & 1 & & & & & 1 \\
\hline Meles $\mathrm{m}$. & 2 & 1 & & & & & 2 \\
\hline Ave & 1 & 1 & & 1 & 1 & & 2 \\
\hline T. identificado & 467 & 26 & 3687 & 135 & 10 & 919 & 602 \\
\hline Indeterminado & 3267 & & 2192 & 1090 & & 855 & 4357 \\
\hline Total & 3734 & & & 1125 & & & 4959 \\
\hline
\end{tabular}

Tabla 3: Distribución de los restos (NR), número mínimo de individuos (NMI) y peso (W) de las distintas especies por niveles / Distribution of remains (NR), minimum number of individuals (MNI) and weight (W) of the different species in each level.

mayor variedad taxonómica. Presenta un herbívoro más (rebeco) y los cuatro carnívoros son exclusivos de este nivel (Tabla III). Esta relación de especies encaja bien con las condiciones paleoclimáticas de inicios del Holoceno y que suele caracterizarse por un mayor protagonismo de especies adaptadas al medio forestal y monte bajo (corzo y jabalí respectivamente).

\subsubsection{Especies cazadas}

El dato más significativo de esta muestra es el predominio de los restos de ciervo en los dos niveles. Si en nivel 1 representa el 83,9\% del total de restos recuperados, en el nivel 3 se convierte en casi la única especie cazada $(91,7 \%)$. Las frecuencias relativas de los demás ungulados son irrelevantes frente a la del ciervo (Tabla IV). Frecuencias de ciervo que superen el $90 \%$ de los restos son

\begin{tabular}{|l|c|c|c|c|c|}
\hline & \multicolumn{2}{|c|}{ Nivel 1 } & \multicolumn{2}{c|}{ Nivel 3 } & TOTAL \\
\hline Ungulados & \%NR & \%W & \%NR & \%W & \%NR \\
\hline Bovini & 0,96 & 1,9 & 0,75 & 6,3 & 0,9 \\
\hline Capra pirenaica. & 0,48 & 0,08 & 5,3 & 1,5 & 1,6 \\
\hline Rupicapra rupicapra & 1,2 & 0,2 & & & 0,9 \\
\hline Cervus elaphus & 83,9 & 91,8 & 91,7 & 92,0 & 85,8 \\
\hline Capreolus capreolus & 7,4 & 3,0 & 2,3 & 0,1 & 6,2 \\
\hline Sus scrofa & 6,0 & 2,9 & & & 4,5 \\
\hline Total de restos & $\mathbf{4 1 7}$ & $\mathbf{3 5 8 9}$ & $\mathbf{1 3 3}$ & $\mathbf{9 1 4}$ & $\mathbf{5 5 0}$ \\
\hline
\end{tabular}

Tabla 4: Frecuencias relativas de los Ungulados por niveles / Ungulate relative frequencies in each level.

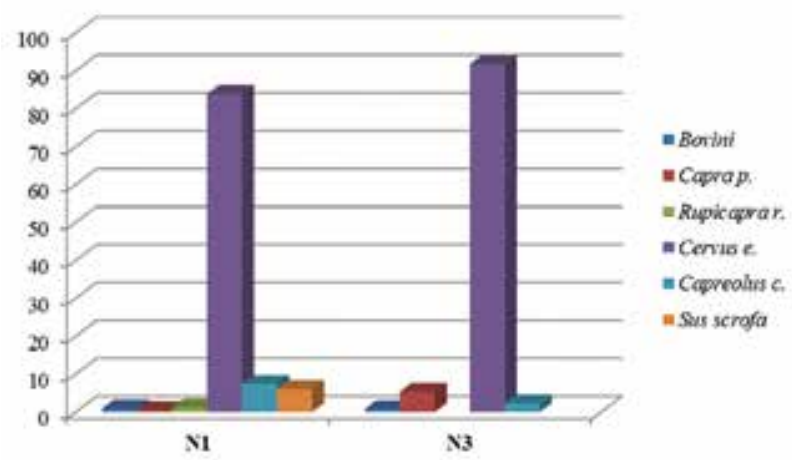

Fig. 11. Gráfica de frecuencias de ungulados por niveles del Carabión / Frequency graph of ungulates per levels in Carabión Rockshelter.

escasas en la Región Cantábrica. Se puede registrar en el yacimiento asturiano de La Paloma (CASTAÑOS, 1980) donde se conserva esta alta proporción a lo largo de todo el Magdaleniense e incluso en el Aziliense.

Este modelo del Carabión confirma una constante descrita en la Región Cantábrica hace décadas. Se trata de una estrategia cinegética típica de los grupos del Paleolítico Superior y del Mesolítico que manifiestan una cierta especialización en la caza del ciervo en los asentamientos de valle y de la cabra montés en yacimientos situados en biotopos de roquedo. El patrón que se observa en Carabión es el más frecuente a lo largo de toda la cornisa cantábrica desde el Magdaleniense hasta el Mesolítico final.

Es interesante cotejar la estructura faunística de Carabión con los datos de niveles mesolíticos de los yacimientos del Norte de la Península lbérica (Fig.12).

Hay muestras como la de Herriko Barra (MARIEZKURRENA; ALTUNA, 1995) en las que el predominio del ciervo es evidente apareciendo casi como la única especie cazada. En Zatoya (MARIEZKURRENA y ALTUNA, 1989), sin embargo, la especie más cazada es el jabalí tanto en el Epipaleolítico como sobre todo en el Neolítico con proporciones muy bajas del resto de las especies. Un tercer modelo se observa en Los Canes

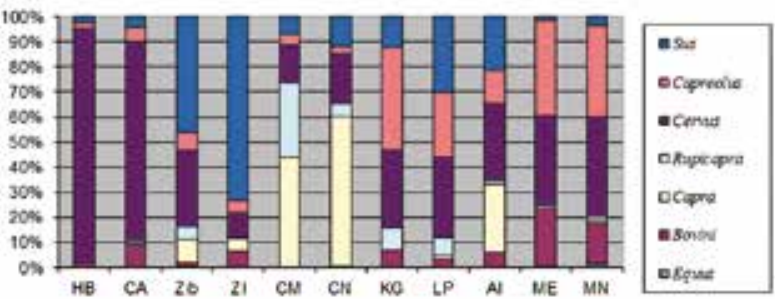

Fig. 12. Histogramas de frecuencias relativas de Ungulados salvajes en varios yacimientos. HB:Herriko Barra; CA: Carabión; Zib:Zatoya Ib; Zl: Zatoya I; CM: Canes Mesolítico; CN: Canes Neolítico; KG: Kampanoste Goikoa III; LP: La Peña d; Al: Aizpea b inf.; ME: Mendandia Epipaleolítico; MN: Mendandia Neolítico / Histograms of the relative frequencies of wild ungulates at different sites. HB: Herriko Barra; CA: Carabión; Zib: Zatoya Ib; ZI: Zatoya I; CM: Canes Mesolíthic; CN: Canes Neolíthic; KG: Kampanoste Goikoa III; LP: La Peña d; Al: Aizpea b inf.; ME: Mendandia Epipaleolíthic; MN: Mendandia Neolíthic. 
donde la cabra montesa ocupa el primer lugar seguida de lejos por el sarrio en el Mesolítico y por el ciervo en el Neolítico.

Esta concentración en la caza de una especie tiene relación con el biotopo en que se ubica el yacimiento y el predominio de dicha especie en el mismo. El entorno orográfico y ecológico de los tres yacimientos citados es distinto en cada uno de ellos y puede explicar en parte la preferencia por la especie más abundante en cada uno. Sin embargo, puede que no sea el único elemento explicativo ya que también ha de tenerse en cuenta el modelo de explotación del ecosistema por parte del grupo cazador que puede ampliar el abanico de recursos cinegéticos, bien por agotamiento de la fauna dominante tras su explotación intensiva, o por otros motivos.

El modelo de aprovechamiento de Carabión está muy próximo al de Herriko Barra (MARIEZKURRENA y ALTUNA, 1995) y representa la continuación de estrategias cinegéticas centradas preferentemente en la captura del ciervo que son las más frecuentes durante el Tardiglaciar Cantábrico.

\subsubsection{Estrategias de caza}

En el caso de Carabión los únicos datos útiles a este respecto son los del nivel 1. En este nivel hay un conjunto de cinco individuos cazados antes de la madurez sexual. Los ocho restantes se dividen en dos adultos jóvenes, cuatro maduros y dos seniles. Los cinco fragmentos de cuerna en un total de 472 restos indican la casi total ausencia de machos. A partir de estos datos podemos suponer que la mayor parte de los ciervos cazados en el nivel más rico de Carabión son hembras y juveniles. Por tanto las apetencias por los rebaños de hembras y crías ya observadas en algunos niveles del Paleolítico Superior parece que perviven en el Mesolítico.

En cuanto al acarreo de las piezas, se ha podido verificar en el caso del ciervo por la abundancia de restos (Tabla V). El mayor porcentaje lo representa la cabeza por la frecuencia de piezas dentarias aisladas que se han separado de los huesos maxilares post mortem. (23,3 \%). Sin embargo, la región anatómica más interesante para reconstruir el modelo de acarreo de las presas hasta el asentamiento suele ser el tronco representado por las costillas, vértebras y esternón. En el caso de Carabión el tronco está representado por fragmentos que suponen el $16,1 \%$ de los restos totales de ciervo. Esta frecuencia a primera vista puede resultar muy baja y por tanto apoyar la hipótesis de un descuartizado previo al acarreo. Sin embargo, para poder llegar a una conclusión más matizada es necesario cotejar los datos de Carabión con los de yacimientos próximos en el espacio y en el tiempo. Para ello se comparan las frecuencias relativas de las tres regiones del cuerpo (cabeza, tronco y extremidades) de distintos yacimientos mesolí-

\begin{tabular}{|c|c|c|c|c|}
\hline & Nivel 1 & Nivel 3 & Total & Anatomía \\
\hline Cuerna & 2 & 3 & 5 & \multirow{7}{*}{$\begin{array}{c}\text { Cabeza } \\
23,3 \%\end{array}$} \\
\hline Cráneo & 1 & & 1 & \\
\hline Maxilar & 3 & & 3 & \\
\hline Diente a.sup. & 32 & 10 & 42 & \\
\hline Mandíbula & 23 & 4 & 27 & \\
\hline Diente a. inf. & 20 & 10 & 30 & \\
\hline Diente ind. & 1 & 1 & 2 & \\
\hline Vértebras & 54 & 2 & 56 & \multirow{3}{*}{$\begin{array}{c}\text { Tronco } \\
16,1 \%\end{array}$} \\
\hline Costillas & 17 & & 17 & \\
\hline Esternón & 3 & & 3 & \\
\hline Escápula & 4 & & 4 & \multirow{6}{*}{$\begin{array}{l}\text { Brazo } \\
18,9 \%\end{array}$} \\
\hline Húmero & 28 & 10 & 38 & \\
\hline Radio & 15 & & 15 & \\
\hline Ulna & 6 & & 6 & \\
\hline Carpo & 16 & 2 & 18 & \\
\hline Metacarpo & 1 & 7 & 8 & \\
\hline Pelvis & 7 & 1 & 8 & \multirow{8}{*}{$\begin{array}{l}\text { Pierna } \\
19,9 \%\end{array}$} \\
\hline Fémur & 16 & 10 & 26 & \\
\hline Rótula & 3 & & 3 & \\
\hline Tibia & 16 & 17 & 33 & \\
\hline Calcáneo & 4 & 2 & 6 & \\
\hline Astrágalo & & 1 & 1 & \\
\hline Resto tarso & & 1 & 1 & \\
\hline Metatarso & 14 & 2 & 16 & \\
\hline Metap. ind. & 28 & 28 & 56 & \multirow{5}{*}{$\begin{array}{c}\text { Pies } \\
21,8 \%\end{array}$} \\
\hline Falange 1 & 22 & 3 & 25 & \\
\hline Falange 2 & 13 & 1 & 14 & \\
\hline Falange 3 & 6 & & 6 & \\
\hline Sesamoideo & 2 & & 2 & \\
\hline Totales & 357 & 115 & 472 & \\
\hline
\end{tabular}

Tabla 5: Distribución de los restos de ciervo por niveles y regiones del cuerpo / Distribution of red deer remains according to level and body region.

ticos de la Región Cantábrica. Todos los casos excepto el de la cueva de Los Canes son de ciervo (Fig.13).

Hay algunos conjuntos en los que la representación de los elementos del tronco apenas supera el 5\%. En estos casos la mayor parte de las piezas cazadas fueron transportadas al yacimiento tras ser despiezadas. Es el caso del ciervo en el nivel III inferior de Mendandia y de la cabra en la cueva de Los Canes. El caso más extremo de este modelo está representado en Socuevas. Sin embargo, en otras muestras la proporción de fragmentos pertenecientes al esqueleto axial superan el 10\%. Se puede suponer que el acarreo de animales completos al lugar de consumo es más frecuente. Es el caso de Aizpea, Carabión y Herriko Barra. Este patrón está llevado a su máxima expresión en el nivel lb de Zatoya y sobre todo del nivel IV de Mendandia. Conviene anotar que los patrones de acarreo pueden variar con el tiempo en un mismo yacimiento como ocurre en Mendandia con el ciervo. 


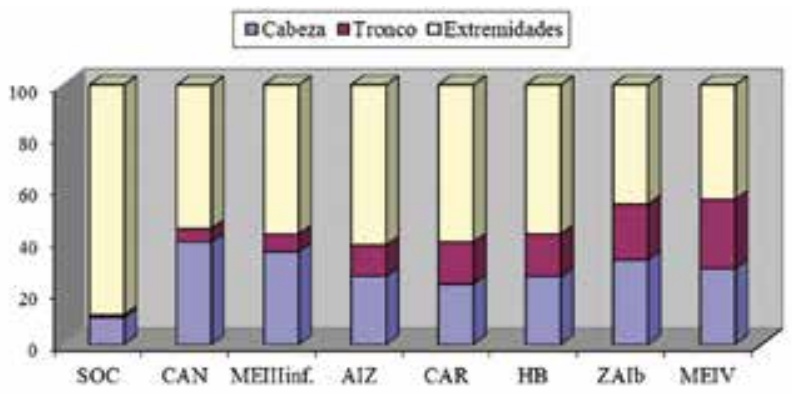

Fig. 13. Porcentajes de las tres regiones del cuerpo en ciervo y cabra (sólo en Canes) de varios niveles mesolíticos (SOC: Socuevas; CAN: Canes: ME: Mendandia; AIZ: Aizpea; CAR: Carabión; HB: Herriko Barra; ZA: Zatoya) / Percentages of the three body regions of red deer and ibex (only at Canes) in different Mesolithic levels (SOC: Socuevas; CAN: Canes; ME: Mendandia; AIZ: Aizpea; CAR: Carabión; HB: Herriko Barra; ZA: Zatoya).

\subsubsection{Patrones de aprovechamiento}

El aprovechamiento más o menos intensivo de las piezas abatidas está en función del grado y tipo de fragmentación observado en las osamentas. Una estimación indirecta de la fragmentación global de la muestra la da el peso medio de los restos identificados frente a los indeterminables. En Carabión los primeros oscilan entre 6,8 y 7,89 gramos mientras que los segundos lo hacen entre 0,67 y 0,78 gramos. Estos resultados son bastante similares entre sí y en general no se alejan de lo que es habitual en yacimientos de ocupación del Paleolítico Superior de la Región Cantábrica.

El tipo de aprovechamiento es de carácter intensivo con rotura sistemática de las cañas de los huesos largos de cara a la obtención de la médula grasa tal como está registrado en otros yacimientos coetáneos de la Península Ibérica.

\subsubsection{Estacionalidad}

Los restos de ciervo del nivel 1 representan un mínimo de 13 individuos: dos infantiles, dos juveniles, un subadulto y ocho adultos, mientras que en el nivel 3 hay dos infantiles, un juvenil y dos adultos (Tabla VI). Estos datos son demasiado escasos para poder esta-

\begin{tabular}{|c|c|c|c|c|}
\hline Dentición & Edad & Nivel 1 & Nivel 3 & Meses de caza \\
\hline D3-4 0 & Neonatos & 2 & 2 & Junio-Julio \\
\hline D3-4 + & $12-20$ meses & 1 & 1 & \\
\hline D3-4 +++ & $20-27$ meses & 1 & & Enero-Agosto \\
\hline M3+-- & $27-30$ meses & 1 & & Sept/ Diciembre \\
\hline M3 + & Más 30 meses & 2 & 1 & \\
\hline M3 ++ & & 4 & & \\
\hline M3 +++ & & 2 & 1 & \\
\hline Total & & 13 & 5 & 18 \\
\hline Juveniles & & 5 & 3 & 8 \\
\hline Adultos & & 8 & 2 & 10 \\
\hline
\end{tabular}

Tabla 6: Estimación de edad de los ciervos del Carabión / Estimates of red deer ages at Carabión Rock shelter. blecer las épocas de caza del ciervo o la posible estacionalidad en la ocupación del yacimiento. Los únicos ejemplares para los que se puede establecer con cierta precisión el momento de la caza son los neonatos.

\subsection{Malacofauna}

La muestra total estudiada asciende a 8.288 restos que se corresponden con un NMI de 1219. Todo el conjunto procede de una misma unidad estratigráfica el nivel 1, un paquete de $40 \mathrm{~cm}$ de potencia sin discontinuidades deposicionales (Tabla VII).

En el conjunto se han cuantificado 19 taxones: 10 bivalvos, 7 gasterópodos, 1 crustáceo, y 1 gasterópodo terrestre. La especie más abundante es el gasterópodo terrestre Cepaea nemoralis $(37,57 \%$ del NMI). El grupo de los bivalvos marinos (54,30\% del $\mathrm{NMI}$ ), es el que tiene mayor representación y dentro del grupo Scrobicularia plana es la especie más frecuente $(21,16 \%$ del NMI), seguida de Ostrea edulis (10,99\%). Mytilus, también están bien representado (9,84\%). En menor pro-

\begin{tabular}{|c|c|c|}
\hline \multicolumn{3}{|c|}{ Carabión N 1} \\
\hline Bivalvos marinos & NMI & $\%$ \\
\hline Cerastoderma edule & 1 & 0,08 \\
\hline Eastonia rugosa & 1 & 0,08 \\
\hline Hiatella arctica & 4 & 0,32 \\
\hline Mytilus sp. & 120 & 9,84 \\
\hline Ostrea edulis & 134 & 10,99 \\
\hline Parvicardium & 1 & 0,08 \\
\hline Pholas dactilus & 1 & 0,08 \\
\hline Ruditapes decussatus & 81 & 6,64 \\
\hline Scrobicularia plana & 258 & 21,16 \\
\hline Solem marginatus & 61 & 5 \\
\hline Total Bivalvos & 662 & 54,30 \\
\hline \multicolumn{3}{|l|}{ Gasterópodos marinos } \\
\hline Littorina saxatalis & 1 & 0,08 \\
\hline Nassarius reticulatus & 5 & 0,4 \\
\hline Phorcus lineatus & 29 & 2,37 \\
\hline Patella vulgata & 3 & 0,24 \\
\hline Patella intermedia & 23 & 1,88 \\
\hline Patella ulyssiponensis. & 4 & 0,32 \\
\hline Patella sp. & 33 & 2,70 \\
\hline Total gasterópodos marinos & 98 & 8,03 \\
\hline \multicolumn{3}{|l|}{ Gasterópodos terrestres } \\
\hline Cepaea nemoralis & 458 & 37,57 \\
\hline Total gasterópodos terrestres & 458 & 37,57 \\
\hline \multicolumn{3}{|l|}{ Crustáceos } \\
\hline Brachyura sp. & 1 & 0,08 \\
\hline TOTAL & 1.219 & 100 \\
\hline
\end{tabular}

Tabla 7: Frecuencias de taxones de malacología. En el N1 del Carabión / Frequencies of malacology taxa in Carabión N1. 
porción Ruditapes decussatus $(6,64 \%)$ y Solem marginatus (5\%).

Los gasterópodos marinos son escasos (8,03\%), siendo Patellae $(5,14 \% \mathrm{NMI})$ la especie más frecuente, aunque en proporción muy baja. De ellas puede realizarse una asignación específica para 30 conchas, que corresponden en su mayor parte a $P$. intermedia $(76.6 \%)$, seguida de $P$. ulyssiponensis (13\%) y de $P$. vulgata (10 $\%)$. Phorcus lineatus es el menos frecuente $(2,37 \%$ del NMI). La frecuencia media de Phorcus lineatus en Carabión es muy reducida, y resulta significativa, ya que esta especie, junto con Patellae, suelen ser las más abundantes en los concheros mesolíticos de la región cantábrica.

Entre los crustáceos se ha identificado un resto de Carcinus maenas y presencia de Balanus balanoides, que han debido de llegar adheridos a conchas de mayor tamaño de interés alimenticio. El resto de las especies es testimonial, si bien hay que destacar la presencia de Eastonia rugosa, especie que no se ha identificado en yacimientos de la región. También se ha recuperado un resto de cefalópodo, una pieza de ventosa procedente de un tentáculo de Octopus vulgaris.

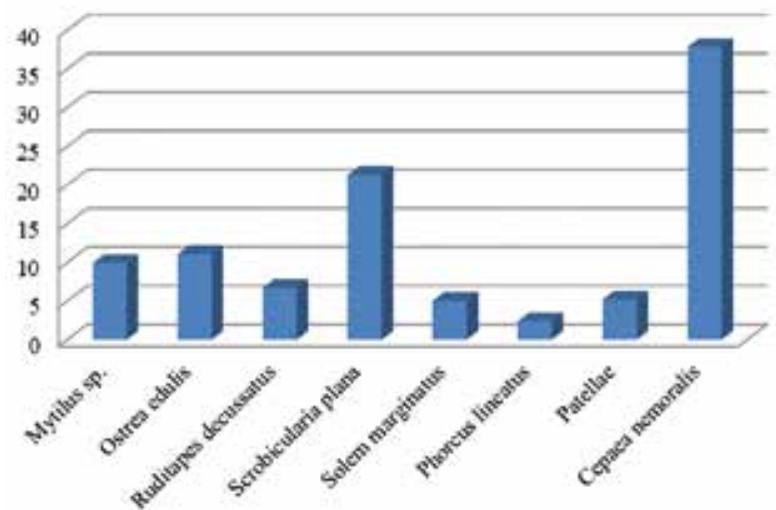

Fig. 14. Gráfica de frecuencias de taxones de malacofauna del N. 1 de Carabión / Frequencies of malacofauna taxa in Level 1 at Carabión Rockshelter.

\subsubsection{Patrón de explotación de los recursos marinos}

El patrón de explotación de la fauna marina revela, que a lo largo de la secuencia tres biotopos han aportado la mayor parte de los recursos malacofaunísticos: el ámbito continental, el estuario y el ambiente mixto, producido en el entorno de los estuarios (Mytilus y Ostrea). Aunque el mayor aporte medio es continental, con casi el $38 \%$ de los restos, el valor del estuario es muy similar, con la tercera parte del total. El entorno mixto ha proporcionado la quinta parte del total. Estos valores son relativamente variables en las diferentes tallas, y en algunas, el dominio es para el estuario puro, es decir, las Ilanuras de limos y fangos del estuario del Asón. En cuando al biotopo de acantilado su aportación en el Carabión es mucho más limitada, con una media del 8\%.

La situación del Carabión en el área de influencia de las rías y marismas, se ve reflejada en el incremento de las especies de estuario (Ostrea edulis), de fangos y arenas (Scrobicularia plana, Ruditapes decussatus y Solem marginatus), presentes en el entorno del estuario del Asón, con influencia en los valles interiores, muy evidente en el valle de Aras-Voto (yacimientos del Carabión, Chora, Trampascuevas, Llanío, Cierro), incluso ascienden hacia el interior hasta unos $20 \mathrm{~km}$, con presencia en Cofresnedo, Cubillo y, abundante en Tarrerón. Las fechas disponibles para algunos de estos yacimientos se encuentran dentro del espacio cronológico posterior a la formación del Estuario del Asón y las Marismas de Santoña, hacia el 8.5 ka BP.

\subsection{Ictiofauna}

La muestra estudiada procede de dos cuadros contiguos, D5 y C5. En ningún caso pudieron realizarse mediciones debido al estado de conservación de los restos. A pesar de ello, se ha intentado estimar la talla para algunos elementos por comparación. Es por tal razón que la talla estimada lo es siempre de modo aproximativo.

Debido al minúsculo tamaño muestral, que impide una estimación fiable del NMI, el parámetro de estimación de abundancia ha sido en todos los casos el número de restos, cuyas bases metodológicas pueden consultarse en CLASON (1972) y WHEELER \& JONES (1989), entre otros.

\subsubsection{Resultados}

Casi el $60 \%$ de la muestra (12 piezas; $57 \%$ del total estudiado) está constituido por vértebras. Les siguen 4 piezas del esqueleto craneal (19\% del total estudiado) y 2 elementos de los radios de las aletas (9'5\%). En ge-

\begin{tabular}{|l|c|c|c|}
\hline \multicolumn{1}{|c|}{ TAXÓN } & NIVEL & NR & $\%$ \\
\hline Anguilla anguilla & Mesolítico & 2 & 22 \\
\hline \multirow{2}{*}{ Chelon labrosus } & Mesolítico & 2 & 12 \\
& Meso-Neolítico & 1 & 11 \\
\hline Liza sp. & Mesolítico & 1 & 11 \\
\hline Mugilidae & Aziliense & 2 & 22 \\
\hline Sparidae & Mesolítico & 1 & 11 \\
\hline Sin identificar & Aziliense & 12 & 57 \\
\hline Total estudiado & - & $\mathbf{2 1}$ & 100 \\
\hline
\end{tabular}

Tabla 8: Relación general de la ictiofauna del Carabión (porcentajes sobr el total de restos identificados (9) / General classification of ichthyofauna in Carabión Rockshelter (percentages of the total number of identified remains $=9$ ). 
neral, todos los huesos son de reducido tamaño y todos se encuentran, en mayor o menor medida, fracturados. Esta es la principal razón por la que casi el $60 \%$ de la muestra no pudo ser identificada taxonómicamente y lo que explica que casi la quinta parte del total estudiado (4 piezas) ni tan siquiera haya podido ser identificada anatómicamente.

La mayoría de los ejemplares son de talla reducida (inferior a los $40 \mathrm{~cm}$ ) y ello plantea dudas acerca de la naturaleza del agente recolector.

1. Anguilla anguilla: las dos vértebras representan animales pequeños o muy pequeños, siempre por debajo de los $20 \mathrm{~cm}$, que supondrían pesos en torno a los 10 gramos.

2. Esparidae: la pieza bucal (dentada) representa un ejemplar de talla y peso indeterminado.

3. Chelon labrosus: las dos vértebras pertenecen a ejemplares comprendidos entre los $35-45 \mathrm{~cm}$, con pesos que se situarían en torno a los 500 gramos.

4. Liza sp:: se trata de una vértebra de un ejemplar en torno a los $45 \mathrm{~cm}$ y un peso entre los 500-800 gramos.

5. Mugilidae: Estos peces determinados a nivel de familia estarían, como los de los géneros Liza y Chelon, en tallas medias comprendidas entre los $30-40 \mathrm{~cm}$ y con pesos comprendidos entre 250-500 gramos.

Aunque la ictiofauna del Carabión es menguada, es evidente el dominio de los mújoles (66\% de lo identificado). El hecho resulta más llamativo porque sólo en otro yacimiento cantábrico, el de Laminak II, próximo a Lekeitio, consta la presencia de estos peces (ROSELLÓ, E,; BRINKHUIZEN, D. 1994) que, sin embargo, no suponen más que un 0'3\% de los más de 7.000 restos de peces documentados en el depósito y son de tallas ligeramente inferiores a los del Carabión $(25-30 \mathrm{~cm}$ de longitud estándar), si bien entran dentro del rango de lo potencialmente capturado por el hombre. Los pocos yacimientos de la Península Ibérica donde los mújoles suponen porcentajes importantes de la ictiofauna los encontramos en los yacimientos mesolíticos Cabezos de Arruda y Amoreira en Portugal que, a pesar de la distancia a la que se encuentran de la actual línea de costa, parece ser que se situaban dentro del régimen de oscilación de las mareas atlánticas en el río Tajo. Y es aquí donde sin duda yace la explicación de la abundancia proporcional de los mugílidos en el Carabión, ya que incluso actualmente, el régimen de mareas en el estuario del Asón tiene influencia en la zona y creemos que en el periodo Mesolítico que nos ocupa, debió de tener mayor amplitud que la actual.

Se da la circunstancia de que la anguila es otro pez anfídromo de hábitos eurihalinos que viene a reforzar tal hipótesis. En el caso del resto de espárido, la morfología remite a un ejemplar de los géneros Pagellus/ Pagrus/Sparus, si bien entre los dos primeros no nos consta ninguna especie como salobre, dentro del tercer género encontramos a la dorada (Sparus aurata), el paradigma de los peces anfídromos, que gusta de frezar en estuarios.

El cuadro paleoecológico por tanto, es el de una ictiofauna asociada a un biotopo de ría o estuario, en donde, por mor de la densidad y tallas que alcanzan, la pesca del mújol hubo de ser una actividad sumamente productiva.

La información de la que disponemos sobre tallas nos indica la posibilidad de que, aunque escasa, la ictiofauna del Carabión nos esté indicando dos vías de llegada al yacimiento. Así, los mújoles parecen haber sido acumulados como restos de una actividad pesquera, por los humanos. Tal hipótesis parece mucho menos probable en el caso de la anguila, cuya diminuta talla, nos lleva a pensar en un tipo de arte de captura diferente a la de los mújoles, lo que nos plantea el enigma de para qué habrían servido unos peces con una minúscula cantidad de carne. Si la presencia de peces minúsculos es debida a la posible actividad de otro agente acumulador en el yacimiento y, por ende, al origen mixto del conjunto íctico (que no sería entonces producto exclusivo de la pesca por parte del hombre). Tal vez estos minúsculos peces pudieran ser restos de descartes pesqueros de algún tipo de arte de enmalle o de empalizadas, situadas en los cursos de agua para interceptar los flujos de peces anfídromos que se producirían con el régimen de mareas. Está claro que son necesarios más datos contextuales para descartar estas hipótesis o, en su caso, perfilar cualquier otra de modo más ajustado a aquella realidad pretérita.

\section{LA INDUSTRIA LÍTICA}

Debido a la escasa superficie excavada son reducidas las colecciones recuperadas en los dos niveles de ocupación. Un rasgo característico es el dominio absoluto del sílex en ambos niveles. La recogida exhaustiva ha permitido recuperar un numeroso conjunto de debrís y restos pequeños $(<1,5 \mathrm{~cm})$.

\subsection{Las industrias del nivel 1}

El conjunto se compone de 203 piezas (Tabla IX), con predominio absoluto del sílex $(92,61 \%)$. En reducida proporción se han utilizado cuarcita $(1,47 \%)$, arenisca $(4,92 \%)$ y cuarzo $(0,98 \%)$. Se encuentra pendiente el estudio del sílex, no obstante, se aprecia la mayor frecuencia del sílex procedente de filones locales del tipo calcedonítico del Cretácico Superior, que se encuentran en la zona costera de Loredo-Langre, con escasa presencia de los del complejo Urgoniano y de sílex foráneos de calidad. El resto de las materias primas, recogidas en forma de canto rodado, proceden del río Asón o de sus afluentes, que discurren próximos a la cavidad.

Los restos de talla son numerosos con 173 piezas $(85,22 \%$ de la industria), además de 8 cantos y 2 frag- 
mentos irregulares. Los soportes que se obtuvieron son mayoritariamente lascas con 44 ejemplares que representan el 25,43 \% de los restos de talla. Hay un equilibrio entre corticales y simples (50\%), la mayoría completas. Los productos laminares son relativamente numerosos con 33 ejemplares (19,07 \% de los restos de talla). Predominan ligeramente las laminillas sobre las láminas (51,51\% dentro del grupo laminar). Las láminas simples superan ligeramente a las corticales $(56,25 \%)$, mientras que las laminillas simples son mucho más numerosas $(82,35 \%$ del grupo de las laminillas). El 37,5 \% de las láminas y el 64,7\% de las laminillas están rotas.

Los chunks, con 29 piezas, la mayoría con córtex, suponen el $16,76 \%$ de los restos de talla. Los debrís son abundantes, con 32 piezas (18,49\%), la mayoría simples. Los fragmentos menores de $1,5 \mathrm{~cm}$ representan el $16,18 \%$ de los restos de talla.

Los núcleos son escasos, con 7 ejemplares (4,04 $\%$ ) dos irregulares y la mayoría son fragmentos o están agotados.

La colección no está facetada (Tabla X). Predominan los talones lisos (32\%). Los talones rotos son también numerosos $(23,71 \%)$, mientras que los facetados son escasos (1,53\%). El índice laminar es alto (ILam: 41,23). Haciendo un análisis comparativo por tallas, se observa en el Abrigo del Carabión que el ILam más elevado se encuentra en la base del conchero, nivel 10, en el cuadro C5 con un índice de 64. En el conjunto total en la base del nivel 1 el ILam se eleva a 80.

\begin{tabular}{|c|c|c|c|c|c|c|}
\hline RESTOS DE TALLA & & & & & & \\
\hline Soportes & Sílex & Calcita & Arenisca & Cuarzo & Total & $\%$ \\
\hline 1. Lascas simples & & & & & 12 & 6,93 \\
\hline a) Completas & 10 & & & & 10 & \\
\hline b) Rotas & 1 & 1 & & & 2 & \\
\hline 2. Lascas $2^{\mathrm{a}}$ & & & & & 15 & 8,67 \\
\hline a) Completas & 10 & & & & 10 & \\
\hline b) Rotas & 5 & & & & 5 & \\
\hline 3. Lascas simp. bord núcleo & & & & & 10 & 5,78 \\
\hline a) Completas & 9 & & & & 9 & \\
\hline b) Rotas & 1 & & & & 1 & \\
\hline 4. Lascas $2^{\mathrm{a}}$ borde núcleo & & & & & 7 & 4,04 \\
\hline a) Completas & 6 & 1 & & & 7 & \\
\hline b) Rotas & & & & & & \\
\hline 5. Láminas simples & & & & & 8 & 4,62 \\
\hline a) Completas & 4 & & & & 4 & \\
\hline b) Rotas & 4 & & & & 4 & \\
\hline 6. Láminas $2^{\mathrm{a}}$ & & & & & 5 & 2,89 \\
\hline a) Completas & & & & & & \\
\hline b) Rotas & 4 & 1 & & & 5 & \\
\hline 7. Lámina simp. bord núcleo & & & & & 1 & 0,59 \\
\hline a) Completas & 1 & & & & 1 & \\
\hline b) Rotas & & & & & & \\
\hline 8. Láminas $2^{\mathrm{a}}$ borde núcleo & & & & & 2 & 1,15 \\
\hline a) Completas & 1 & & & & 1 & \\
\hline b) Rotas & 1 & & & & 1 & \\
\hline 9. Laminillas simples & & & & & 12 & 6,93 \\
\hline a) Completas & 5 & & & & 5 & \\
\hline b) Rotas & 7 & & & & 7 & \\
\hline 10. Laminilla simp. bord. núcleo & & & & & 2 & 1,15 \\
\hline a) Completas & 1 & & & & 1 & \\
\hline b) Rotas & 1 & & & & 1 & \\
\hline 11. Laminillas $2^{a}$ & & & & & 3 & 1,77 \\
\hline a) Completas & 3 & & & & 3 & \\
\hline b) Rotas & & & & & & \\
\hline
\end{tabular}




\begin{tabular}{|c|c|c|c|c|c|c|}
\hline 12. Chunks & & & & & 29 & 16,76 \\
\hline a) Sin córtex & 11 & & & & 11 & \\
\hline b) Con córtex & 18 & & & 1 & 18 & \\
\hline 13. Debris & & & & & 32 & 18,49 \\
\hline a) Sin córtex & 25 & & & & 25 & \\
\hline b) Con córtex & 7 & & & & 7 & \\
\hline 14.- Fragmentos Inf. $1,5 \mathrm{~cm}$ & & & & & 28 & 16,18 \\
\hline a) Con córtex & 4 & & & & 4 & \\
\hline b) Sin córtex & 23 & & & 1 & 24 & \\
\hline 15. Núcleos & & & & & 7 & 4,04 \\
\hline a) Irregulares & 2 & & & & 2 & \\
\hline \multicolumn{7}{|l|}{ b) Sobre lasca } \\
\hline c) Fragmentos & 5 & & & & 5 & \\
\hline 17. Cantos & & & & & 8 & 4,62 \\
\hline a) Completos & & & 3 & & 3 & \\
\hline b) Frag. de canto & & & 5 & & 5 & \\
\hline 18. Fragmentos irregulares & 1 & & 1 & & 2 & 1,15 \\
\hline TOTAL & & & & & 183 & \\
\hline RESTOS DE TALLA & 168 & 3 & & 2 & 173 & 85,22 \\
\hline ÚTILES & 20 & & & & 20 & \\
\hline MACROUTILLAJE & & & 8 & & 8 & \\
\hline FRAGMENTO IRREGULAR & & & 2 & & 2 & \\
\hline TOTAL PIEZAS & 188 & 3 & 10 & 2 & 203 & \\
\hline
\end{tabular}

Tabla 9: Restos de talla del Nivel 1 del Carabión / Debitage waste in Carabión N1.

\begin{tabular}{|l|c|c|c|c|c|c|c|}
\hline & Facetado & Liso & Cortical & Puntiforme & Suprimido & Roto & Total \\
\hline Lascas & & 31 & 9 & 1 & 6 & 10 & 57 \\
\hline Láminas & 1 & 10 & 3 & 5 & 8 & 13 & 40 \\
\hline Total & $\mathbf{1}$ & $\mathbf{4 1}$ & $\mathbf{1 2}$ & $\mathbf{6}$ & $\mathbf{1 4}$ & $\mathbf{2 3}$ & $\mathbf{9 7}$ \\
\hline
\end{tabular}

Tabla 10: Índices de talones y facetaje N1 del Carabión / Butt and facetting indices in Carabión N1.

\subsubsection{La industria retocada}

El utillaje retocado en el N. 1 es escaso. Se han catalogado 20 útiles (10,63\% del total de restos), todos fabricados en sílex, caracterizados según el sistema Sonneville-Bordes y Perrot (1954, 1955,1956a, 1956b) (Tabla XI), a los que hay que añadir 8 cantos, 3 completos y 5 fragmentos, con huellas de percusión en uno de los extremos. En los útiles predomina el soporte sobre lasca con 13 piezas (4 sobre lascas simples, 4 secundarias, 3 simples de borde de núcleo y 2 secundarias de borde de núcleo). Se han fabricado sobre soporte laminar 7 (2 sobre láminas simples, 1 simple de borde de núcleo y 4 laminillas).

El grupo de los raspadores es relativamente numeroso (el $15 \%$ de los útiles). Todos ellos pertenecen a tipos bajos, sobre lasca y unguiforme, muy característicos, destacando uno unguiforme con un pequeño pedúnculo. Los buriles con menor presencia son tam- bién importantes (10\%), uno diedro y otro sobre truncatura. Hay un perforador muy típico (5\%). Las piezas con retoques continuos suponen el $20 \%$. Las piezas de sustrato (escotaduras, astillados y raederas) son abundantes con un $20 \%$ del conjunto del utillaje.

El grupo de los dorsos representa un $15 \%$ con 3 laminillas, y las puntas están representadas con una microgravette.

El único microlito geométrico recuperado, un segmento de círculo con retoque doble bisel, en la parte superior del conchero $(-20 \mathrm{~cm})$, corresponde por la datación obtenida, a un momento de transición al Neolítico.

La colección es reducida para poder ser caracterizada con precisión, si bien es similar a la mayoría de los conjuntos mesolíticos de la región. Así, los raspadores son más numerosos que los buriles, todos ellos planos y de reducido tamaño, destacando la presencia de raspadores unguiformes, uno de ellos pedunculado, como 


\begin{tabular}{|c|l|c|c|}
\hline \multicolumn{2}{|c|}{ Tipología } & No Sílex & $\%$ \\
\hline $\mathbf{8}$ & Raspador sobre lasca & 1 & 5 \\
\hline $\mathbf{1 0}$ & Raspador unguiforme & 2 & 10 \\
\hline $\mathbf{2 3}$ & Perforador típico & 1 & 5 \\
\hline $\mathbf{2 8}$ & Buril diedro central & 1 & 5 \\
\hline $\mathbf{3 5}$ & Buril sobre truncatura retocada convexa & 1 & 5 \\
\hline $\mathbf{5 1}$ & Microgravette & 1 & 5 \\
\hline $\mathbf{6 5}$ & Pieza con retoques continuos en un borde & 3 & 15 \\
\hline $\mathbf{6 6}$ & Pieza con retoques continuos en ambos bordes & 1 & 5 \\
\hline $\mathbf{7 4}$ & Pieza con escotadura & 1 & 5 \\
\hline $\mathbf{7 6}$ & Pieza astillada & 3 & 15 \\
\hline $\mathbf{7 7}$ & Raedera & 1 & 5 \\
\hline $\mathbf{8 3}$ & Segmento de círculo & $\mathbf{3}$ & 5 \\
\hline $\mathbf{8 5}$ & Laminilla de dorso & $\mathbf{2 0}$ & $\mathbf{1 0 0}$ \\
\hline & Total & $5 e q u$ & 5 \\
\hline
\end{tabular}

Tabla 11: Clasificación tipológica de los soportes retocados según el sistema de Sonneville-Bordes y Perrot en el Nivel 1 del Carabión / Typological classification of retouched objects in Carabión N1, according to the Sonneville-Bordes and Perrot system.

ocurre en el abrigo de Barcenilla (Muñoz Fernández et al, 2013), donde aparece otro ejemplar también de tamaño reducido.

Es también un rasgo característico la relativa abundancia de piezas astilladas y de las laminillas de dorso. Sin duda los útiles más interesantes son la punta microgravette y sobre todo el segmento de círculo. La punta es un elemento que se conoce en otros conjuntos, si bien es un útil que se generaliza en el Magdaleniense y sobre todo en el Aziliense. El segmento de círculo es un elemento que aparece durante el Aziliense, siendo muy frecuente en los niveles superiores de las cuevas del Piélago, perdurando hasta el Neolítico. El tipo de retoque suele ser abrupto, apareciendo el retoque a doble bisel en momentos tardíos del Mesolítico y en el Neolítico. La técnica del doble bisel aparece en el Mesolítico del Valle del Ebro de donde al parecer procede lo cantábrico.

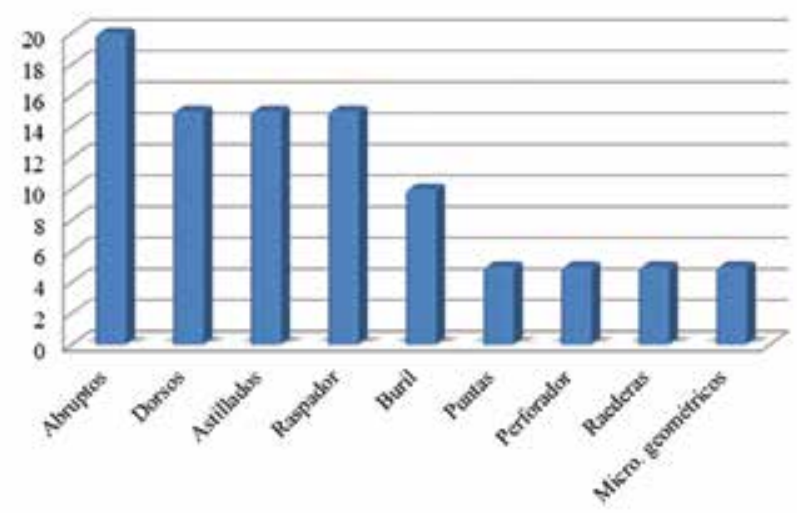

Fig. 15. Gráfica de representación de los índices tipológicos de la industria retocada del N1 del Carabión / Graph representing the typological indices of the retouched assemblage in N1 at Carabión Rockshelter.
La colección a pesar de ser muy corta tiene grandes semejanzas con otras colecciones de la mitad oriental de Cantabria, entre las que destacan las del abrigo de Barcenilla, La Garma A, Cubío Redondo y Tarrerón, todas ellas muy pobres en efectivos líticos.

\subsection{Las industrias del nivel 3}

La industria recuperada en el nivel 3 es relativamente escasa, debido a la reducida superficie excavada (Tabla XII). Se han hallado 613 piezas líticas, con predominio absoluto del sílex (99,34\%), en arenisca (el 0,5 $\%$ ) y 1 canto en lutita (el 0,16 \%). La mayoría de los sílex son de buena calidad, con predominio del tipo flysch, probablemente procedente de Kurtzia, y son frecuentes los sílex calcedoníticos de La Picota-Langre, filones situados en la zona costera, próximos al yacimiento.

Los restos de talla con 543 piezas suponen el 88,58 $\%$ del total de la industria. En los soportes, las lascas son abundantes con 120 ejemplares (22\% de los restos de talla), de ellas las corticales representan el $52.5 \%$ y las simples el 46,66\%; mientras que las lascas primarias están presentes con un solo ejemplar (0,83\% de las lascas).

Los productos laminares con 145 ejemplares son elevados $(26,7 \%$ de los restos de talla). Las láminas (45\% de los productos laminares) son inferiores a las laminillas (60\% de los productos laminares), siendo mucho más numerosas las simples $(88,5 \%)$ que las corticales (11,5\%).

Los chunks representan el 6,63\% de los restos de talla, la mayoría de ellos corticales. La fracción debrís tiene un índice alto $(27,73 \%)$, la mayoría simples. Los fragmentos son también abundantes $(20,44 \%)$ y los golpes de buril solamente están representados con 4 piezas $(0,73 \%)$.

Los núcleos son escasos (2,2\% de los restos de talla), uno de ellos prismático, bipolar, con abundantes extracciones de láminas y laminitas, muy agotado. La mayoría son irregulares, salvo uno sobre lasca roto.

La colección presenta un índice laminar muy alto (ILám: 54,71), siendo una industria claramente laminar. No está facetada (índice de facetaje estricto: 0,75 e índice de facetaje amplio: 6,41). Predominan los talones lisos (el 63,01\%), siendo frecuentes los suprimidos (el $15,09 \%$ ) y los puntiformes (el 10,56 \%) (Tabla XIII).

\subsubsection{La industria retocada}

Los útiles son porcentualmente numerosos, con 70 ejemplares lo que supone el 11,14\% del registro lítico. Con todo, la colección es pequeña para poder extraer conclusiones definitivas (Tabla XIV). Predominan los útiles sobre soporte laminar $(59,42 \%)$, con predominio de las laminillas (31,88 \%) sobre las láminas (26,47\%), siendo más abundantes las simples que las corticales. Los útiles sobre lasca son menos frecuentes (40\%), con mayor presencia de las corticales, dos de ellas primarias. 


\begin{tabular}{|c|c|c|c|c|}
\hline \multicolumn{5}{|c|}{ INDUSTRIA LÍTICA ABRIGO DEL CARABIÓN N3 } \\
\hline RESTOS DE TALLA & Sílex & Arenisca & $\Sigma$ & $\%$ \\
\hline 1. Lasca primaria & & & 1 & 0,18 \\
\hline a) Completas & 1 & & 1 & \\
\hline \multicolumn{5}{|l|}{ b) Rotas } \\
\hline 2. Lascas simples & & & 37 & 6,81 \\
\hline a) Completas & 18 & & 18 & \\
\hline b) Rotas & 19 & & 19 & \\
\hline 3. Lascas $2^{a}$ & & & 36 & 6.62 \\
\hline a) Completas & 18 & 2 & 20 & \\
\hline b) Rotas & 15 & 1 & 16 & \\
\hline 4. Lascas simple borde de núcleo & & & 19 & 3,49 \\
\hline a) Completas & 17 & & 17 & \\
\hline b) Rotas & 2 & & 2 & \\
\hline 5. Lascas $2^{a}$ borde núcleo & & & 27 & 4,97 \\
\hline a) Completas & 25 & & 25 & \\
\hline b) Rotas & 2 & & 2 & \\
\hline 6. Láminas simples & & & 29 & 5,34 \\
\hline a) Completas & 9 & & 9 & \\
\hline b) Rotas & 20 & & 20 & \\
\hline 7. Láminas $2^{\mathrm{a}}$ & & & 16 & 2,94 \\
\hline a) Completas & 10 & & 10 & \\
\hline b) Rotas & 6 & & 6 & \\
\hline 8. Lámina simple borde de núcleo & & & 9 & 1,46 \\
\hline a) Completas & 7 & & 7 & \\
\hline b) Rotas & 2 & & 2 & \\
\hline 9. Láminas $2^{\mathrm{a}}$ borde de núcleo & & & 4 & 0,73 \\
\hline a) Completas & 3 & & 3 & \\
\hline b) Rotas & 1 & & 1 & \\
\hline 10. Laminillas simples & & & 58 & 10,68 \\
\hline a) Completas & 14 & & 17 & \\
\hline b) Rotas & 41 & & 41 & \\
\hline 11.Laminilla simple borde de núcleo & & & 19 & 3,49 \\
\hline a) Completas & 13 & & 13 & \\
\hline b) Rotas & 6 & & 6 & \\
\hline 12. Laminillas $2^{\mathrm{a}}$ & & & 4 & 0,73 \\
\hline a) Completas & 3 & & 3 & \\
\hline b) Rotas & 1 & & 1 & \\
\hline 13. Laminillas $2^{\mathrm{a}}$ borde de núcleo & & & 6 & 1,1 \\
\hline a) Completas & 6 & & 6 & \\
\hline \multicolumn{5}{|l|}{ b) Rotas } \\
\hline 14. Chunks & & & 33 & 6,07 \\
\hline a) Sin córtex & 13 & & 13 & \\
\hline b) Con córtex & 20 & & 20 & \\
\hline 15. Debrís & & & 118 & 27,73 \\
\hline a) Sin córtex & & & 107 & \\
\hline b) Con córtex & & & 11 & \\
\hline 16. Golpe de buril & 4 & & 4 & 0,73 \\
\hline
\end{tabular}




\begin{tabular}{|c|c|c|c|c|}
\hline 17.- Fragmentos Inf. $1,5 \mathrm{~cm}$ & & & 111 & 20,44 \\
\hline a) Con córtex & 20 & & 20 & \\
\hline b) Sin córtex & 91 & & 91 & \\
\hline 18. Núcleos & & & 12 & 2,2 \\
\hline a) Irregulares & 10 & & 10 & \\
\hline b) Sobre lasca & 1 & & 1 & \\
\hline \multicolumn{5}{|l|}{ c) Fragmentos } \\
\hline d) Prismático & 1 & & 1 & \\
\hline 19. Cantos & 1 & & 1 & \\
\hline a) Completos & & & 1 & \\
\hline \multicolumn{5}{|l|}{ b) Rotos } \\
\hline TOTAL & 541 & 3 & 544 & \\
\hline RESTOS DE TALLA & & & 543 & \\
\hline ÚTILES & & & 69 & \\
\hline MACROUTILLAJE & & & 1 & \\
\hline TOTAL PIEZAS & & & 613 & \\
\hline
\end{tabular}

Tabla 12: Restos de talla del N3 del Carabión / Debitage waste in Carabión N3.

\begin{tabular}{|l|c|c|c|c|c|c|c|c|c|}
\hline & Facetado & Convexo & Diedro & Liso & Cortical & Puntiforme & Suprimido & Roto & Total \\
\hline Lascas & 1 & 1 & 13 & 74 & 11 & 7 & 22 & 26 & 155 \\
\hline Láminas & - & - & 2 & 93 & 2 & 21 & 18 & 46 & 182 \\
\hline Total & 1 & 1 & 15 & 167 & 13 & 28 & 40 & 72 & 337 \\
\hline
\end{tabular}

Tabla 13: Índices de Talones y facetaje del N3 del Carabión / Butt and facetting indices in Carabión N3.

\begin{tabular}{|c|c|c|c|c|c|}
\hline \multicolumn{2}{|c|}{ Tipología } & Sílex & Otros & Total & $\%$ \\
\hline \multicolumn{2}{|c|}{ Raspadores } & & & & 11,42 \\
\hline 1 & Raspador simple & 1 & & 1 & 1,42 \\
\hline 2 & Raspador atípico & 1 & & 1 & 1,42 \\
\hline 8 & Raspador sobre lasca & 3 & & 3 & 4,28 \\
\hline 10 & Raspador unguiforme & 1 & & 1 & 1,42 \\
\hline 12 & Raspador carenado atípico & 1 & & 1 & 1,42 \\
\hline 18 & Raspador-truncatura & 1 & & 1 & 1,42 \\
\hline \multicolumn{2}{|c|}{ Buriles } & & & & 10 \\
\hline 48 & Punta de la Gravette & 1 & & 1 & 1,42 \\
\hline 51 & Microgravette & 2 & & 2 & 2,85 \\
\hline 91 & Punta aziliense & 1 & & 1 & 1,42 \\
\hline \multicolumn{2}{|c|}{ Lámina de borde abatido } & & & & 4,28 \\
\hline 58 & Pieza de borde abatido total & 2 & & 2 & 2,85 \\
\hline 59 & Pieza de borde abatido parcial & 1 & & 1 & 1,42 \\
\hline \multicolumn{2}{|c|}{ Truncaduras } & & & & 7,14 \\
\hline 60 & Pieza con truncadura recta & 2 & & 2 & 2,85 \\
\hline 61 & Pieza con truncadura oblicua & 3 & & 3 & 4,28 \\
\hline 84 & Laminilla truncada & & & & \\
\hline \multicolumn{2}{|c|}{ Retoque abrupto } & & & & 20 \\
\hline 65 & Pieza con retoques continuos en un borde & 13 & & 13 & 18,57 \\
\hline 66 & Pieza con retoques continuos en ambos bordes & 1 & & 1 & 1,42 \\
\hline \multicolumn{2}{|c|}{ Muescas y denticulados } & & & & 4,28 \\
\hline 74 & Pieza con escotadura & 2 & & 2 & 2,85 \\
\hline 75 & Denticulado & 1 & & 1 & 1,42 \\
\hline
\end{tabular}




\begin{tabular}{|l|l|c|c|c|c|}
\hline \multicolumn{2}{|l|}{ Diversos } & & & & $\mathbf{1 , 4 2}$ \\
\hline 92 & Canto & & 1 lutita & 1 & 1,42 \\
\hline & Total & $\mathbf{6 9}$ & $\mathbf{1}$ & $\mathbf{7 0}$ & $\mathbf{1 0 0}$ \\
\hline
\end{tabular}

Tabla 14: Clasificación tipológica de los soportes retocados según el sistema de Sonneville-Bordes y Perrot en el Nivel 3 del Carabión / Typological classification of retouched objects in Carabión N3, according to the Sonneville-Bordes and Perrot system.

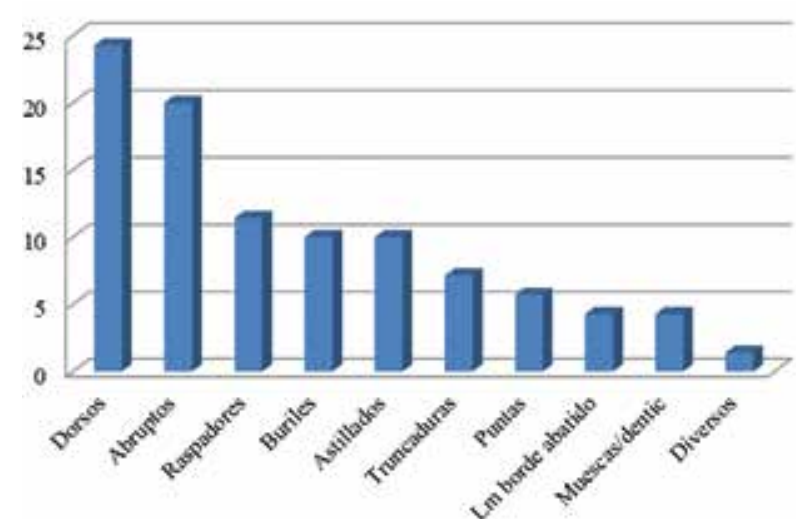

Fig. 16. Gráfica de índices de tipología lítica del N. 3 del Carabión / Graph with lithic typology indices in Carabión N3.

Los raspadores son relativamente numerosos, con 8 ejemplares $(\mathrm{IG}=11,42)$. Todos ellos son planos salvo uno carenado atípico. Aunque pertenecen a distintos tipos predomina el tipo sobre lasca (5). Destaca la presencia de uno unguiforme y de uno atípico sobre lámina, bastante alto. Además hay una lámina con un raspador simple en un extremo y una truncatura retocada.

Los buriles son también numerosos $(I B=10)$. Predominan los de truncatura frente a los diedros y son frecuentes los planos. Están realizados tanto sobre lasca como sobre lámina, destacando uno múltiple sobre truncatura realizado en una lámina con retoques simples directos en un borde y uno carenado plano sobre fractura natural, con varios golpes de buril.

Hay varias piezas con retoque abrupto, unas con el borde abatido y otras con truncadura retocada. Las piezas con retoques continuos en los bordes son muy numerosas (20\%). Hay 6 lascas y 8 láminas, de las cuales 4 presentan retoques simples (3 directos, incluyendo una lámina con retoques en ambos bordes y uno con los retoques inversos) y 10 tienen retoques marginales, todos ellos directos salvo uno inverso.

Las muescas y denticulados están escasamente presentes $(4,28 \%)$. Son numerosas las piezas astilladas (10\%) y las truncaduras suponen el 7,14\%.

En el grupo de las puntas hay una Gravette, dos microgravettes y una punta aziliense, todas ellas muy características. Las laminillas retocadas son frecuentes, especialmente las laminillas de dorso (24,28 \%), siendo el útil más abundante de la colección. Además hay una laminilla truncada y una laminilla de dorso truncada.

El grupo de los diversos está escasamente representado con un canto compresor de lutita roto.
La colección a pesar de ser muy corta resulta característica del Aziliense, sin que se pueda precisar más.

El material retocado es porcentualmente muy abundante, predominando el utillaje sobre laminillas, siendo las de dorso el útil más numeroso, destacando la presencia de puntas microgravette y aziliense. Los raspadores, mayoritariamente sobre lasca, con presencia del tipo unguiforme, tienen un índice ligeramente superior al de los buriles, lo que es poco frecuente en el Aziliense Cantábrico, salvo en el área vasca. Predominan los buriles sobre truncadura frente a los diedros, otro aspecto que le aproxima a los conjuntos del Cantábrico Oriental. En el resto de útiles destaca la abundancia de piezas con retoques continuos en un borde y las piezas astilladas, ambos tipos comunes en otros conjuntos azilienses.

\section{EL DEPÓSITO FUNERARIO}

Los restos humanos se encontraban en el extremo oeste del abrigo, cuadro 11 a $-10 \mathrm{~cm}$, en un cubículo muy alterado por erosión hidrológica. En esta zona el conchero presenta una potencia de 0,30 m por encima del nivel 0. La alteración sufrida por el yacimiento en este área, no ha permitido identificar el tipo de inhumación, parece que fue depositado en el interior del conchero.

Se han recuperado seis fragmentos craneales que se relacionan anatómicamente y pertenecen al área bregmática en la bóveda del cráneo, representan una parte menor de ambos parietales. Pertenecen a un cráneo de edad juvenil a juzgar por la permeabilidad de las suturas visibles, esto es la sagital y la coronal, que muestran interdigitaciones características o ausencia de sinostosis, sin poder precisar el sexo debido a la escasa evidencia de los restos. En su conjunto, los seis fragmentos de ambos parietales alcanzan una longitud anteroposterior de $102 \mathrm{~mm}$ y una anchura de $146 \mathrm{~mm}$ (56 $\mathrm{mm}$ del parietal derecho y $90 \mathrm{~mm}$ del parietal izquierdo).

Por otra parte, los huesos muestran la acción del fuego tanto en la tabla externa, en donde predomina una zona de color negruzco desigualmente distribuida, como de la tabla interna en donde la coloración es tostada y brillante de forma homogénea con aspecto cristalino en la cortical del hueso. Todo lo anterior se interpreta como consecuencia de que el cráneo, o parte de él, se ha visto afectado por el calor de un fuego en su inmediata proximidad muy probablemente de forma casual o accidental cuando ya no conservaba partes blandas, es decir, en estado de esqueletización completa. La temperatura a la que habrían sido sometidos los restos no superaría los $200^{\circ} C^{\circ}$ (Etxeberría, 1994). 


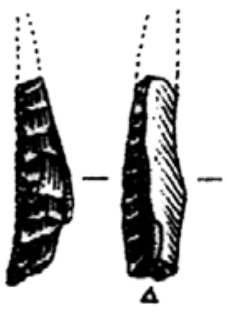

10

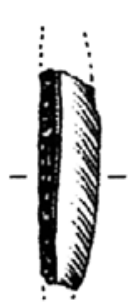

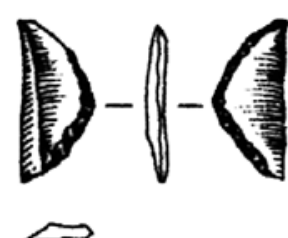

3

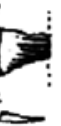

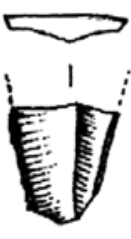

$\Delta$

5

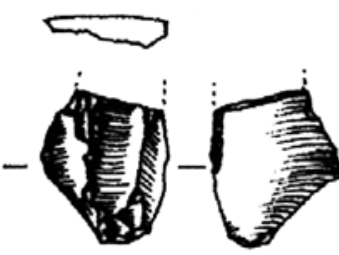

6

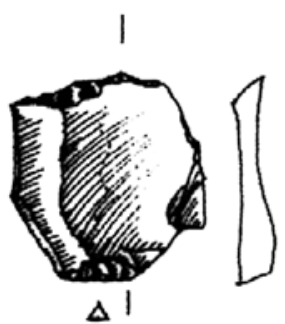

7

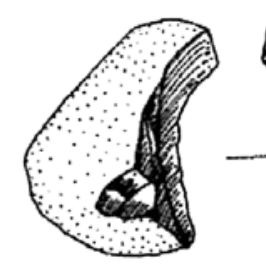

8
4
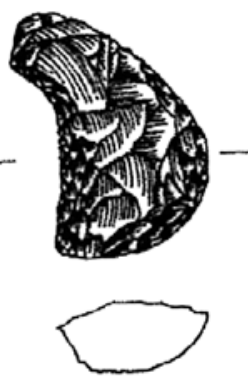
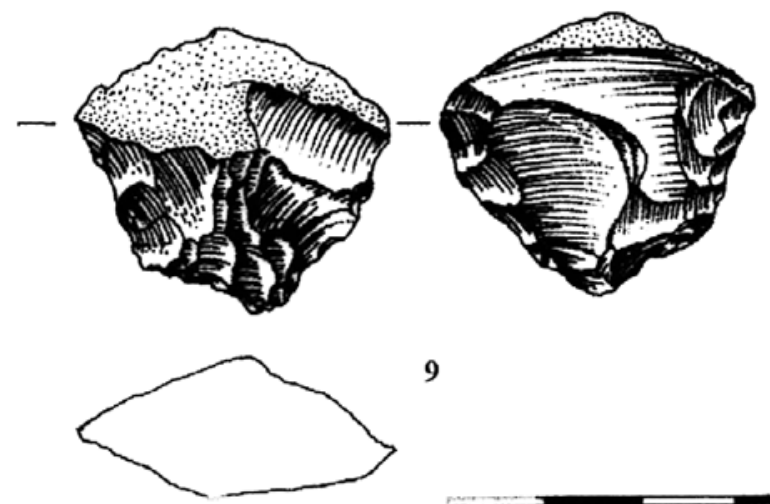

9
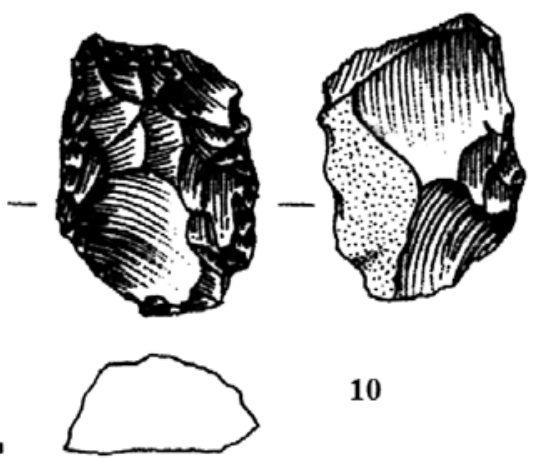

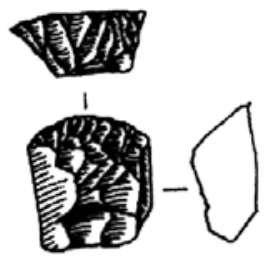

11
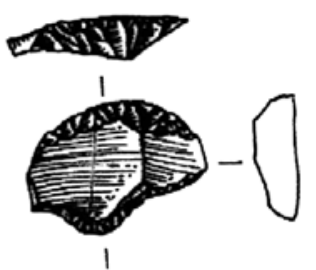

12

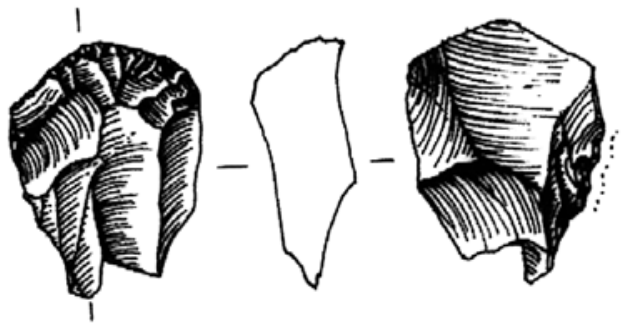

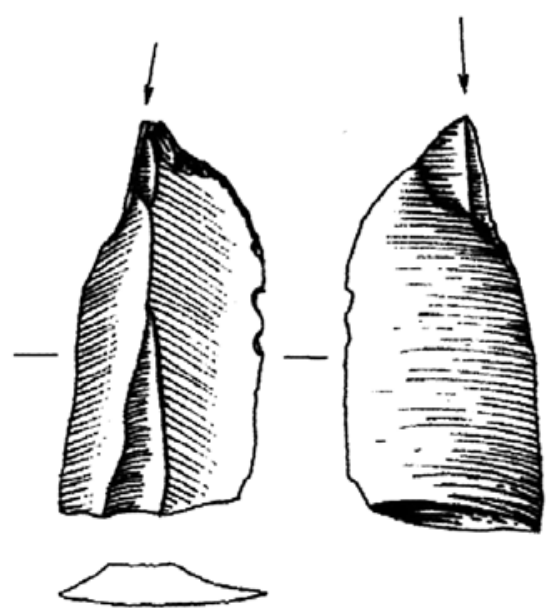

14

13

Fig. 17. Industria lítica retocada N1 del Carabión: Microgravette (1 rota); Segmento de círculo (3); Laminillas de dorso (2,4); Raspadores (11-12-13); Buril (14); Retoque marginal (5-6); Astillados (7, 8,9); Raedera carenada (10) / Retouched lithic assemblage in Carabión N1: microgravette (1, broken); circle segment (3); backed bladelets (2, 4); endscrapers (11, 12, 13); burin (14), marginal retouch $(5,6)$; splintered pieces $(7,8)$; carinated sidescraper (10). 

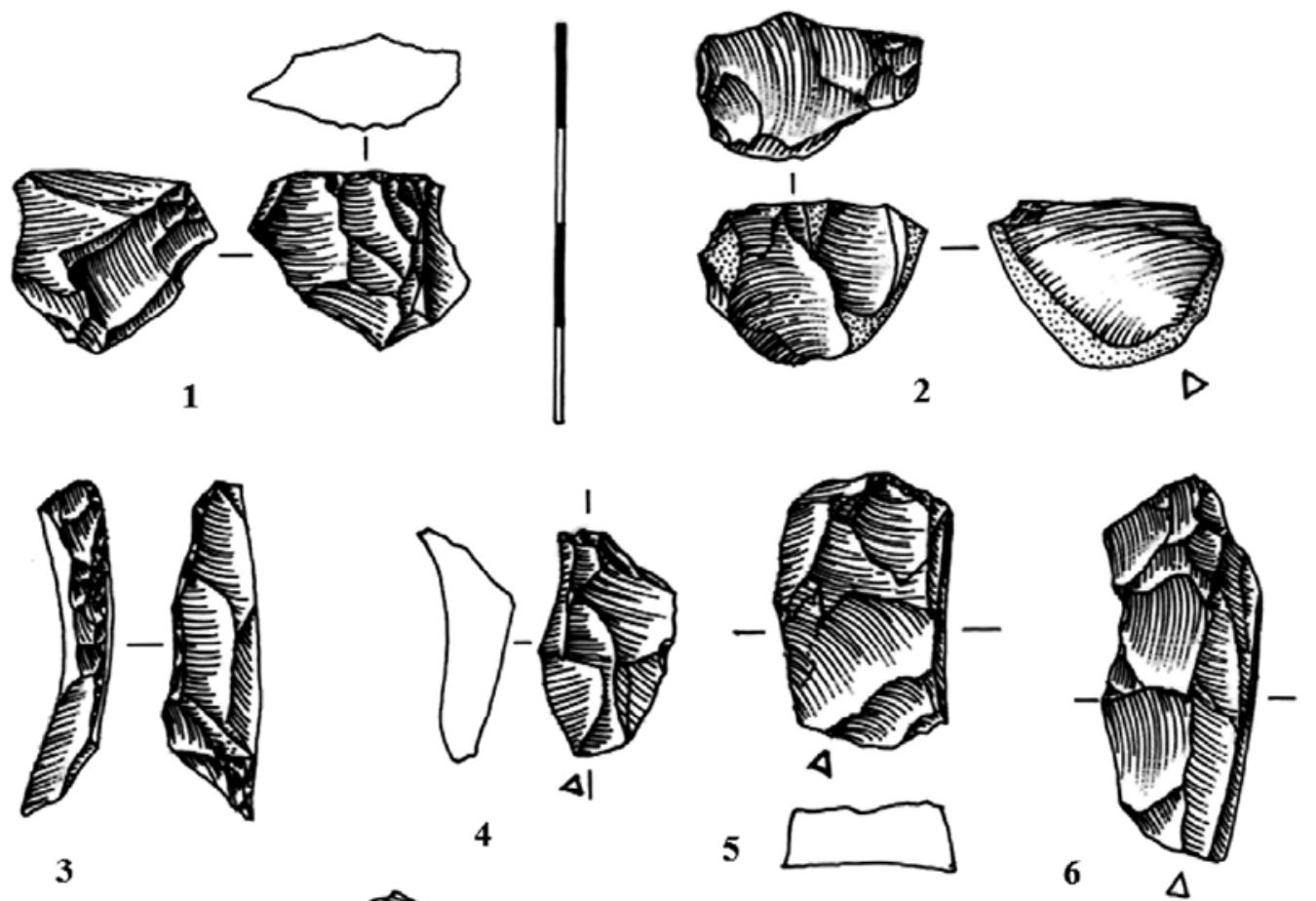

3

4
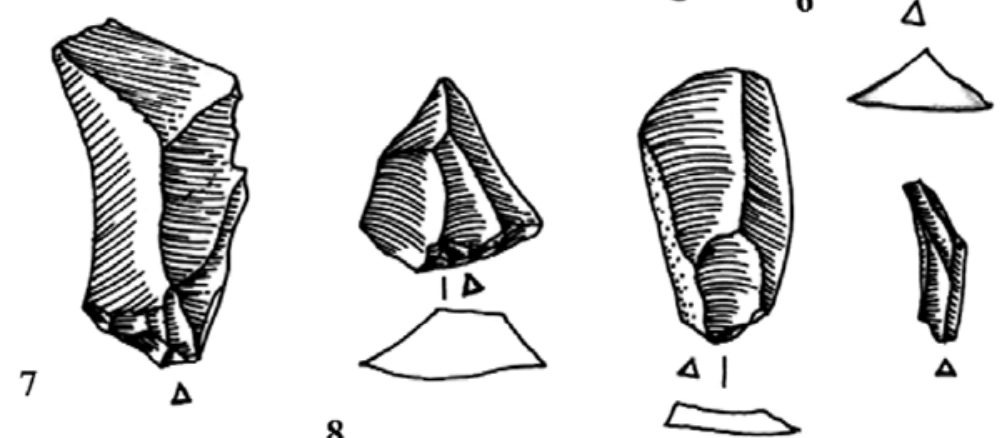

8
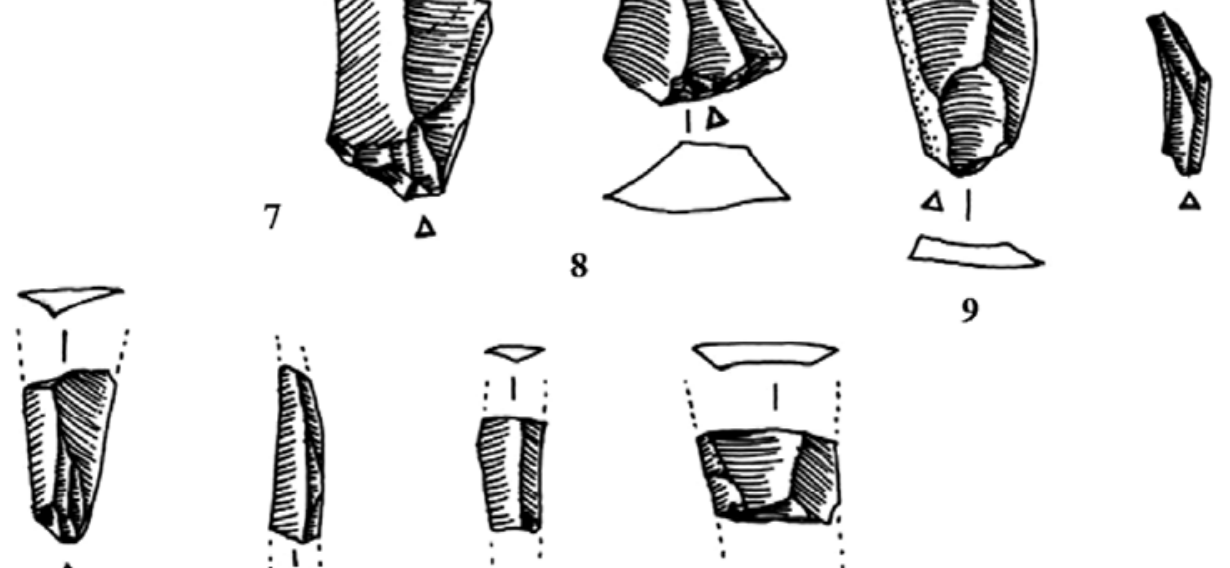

11

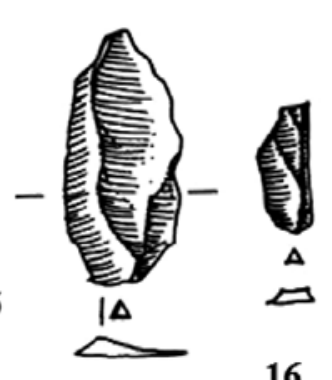

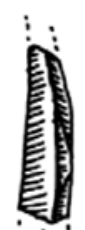

人:

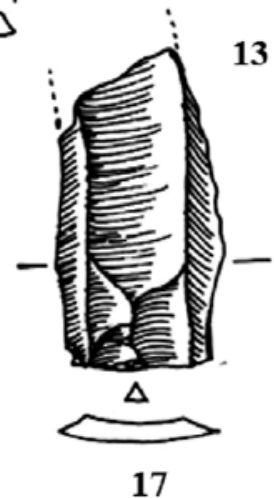

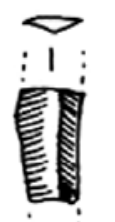

13

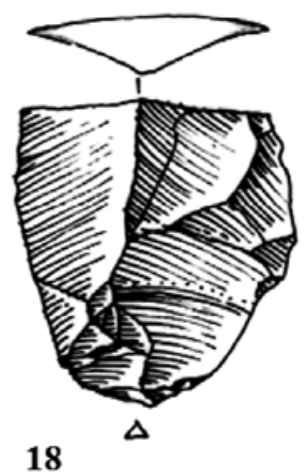

19
14

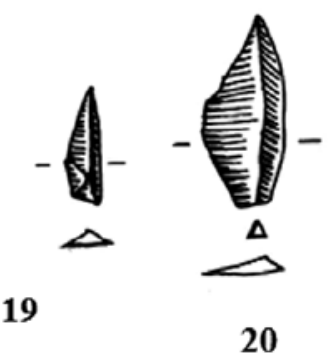

Fig. 18. Industria lítica del Carabión C5 N1: 1-2 Núcleos irregulares (agotados); Lascas (3-6 y 8); Industria laminar (7 y 9-20) / Lithic assemblage from Carabión C5 N1: irregular cores (exhausted) (1-2); second core edge flakes (3-6, 8); blades (7, 9-20). 

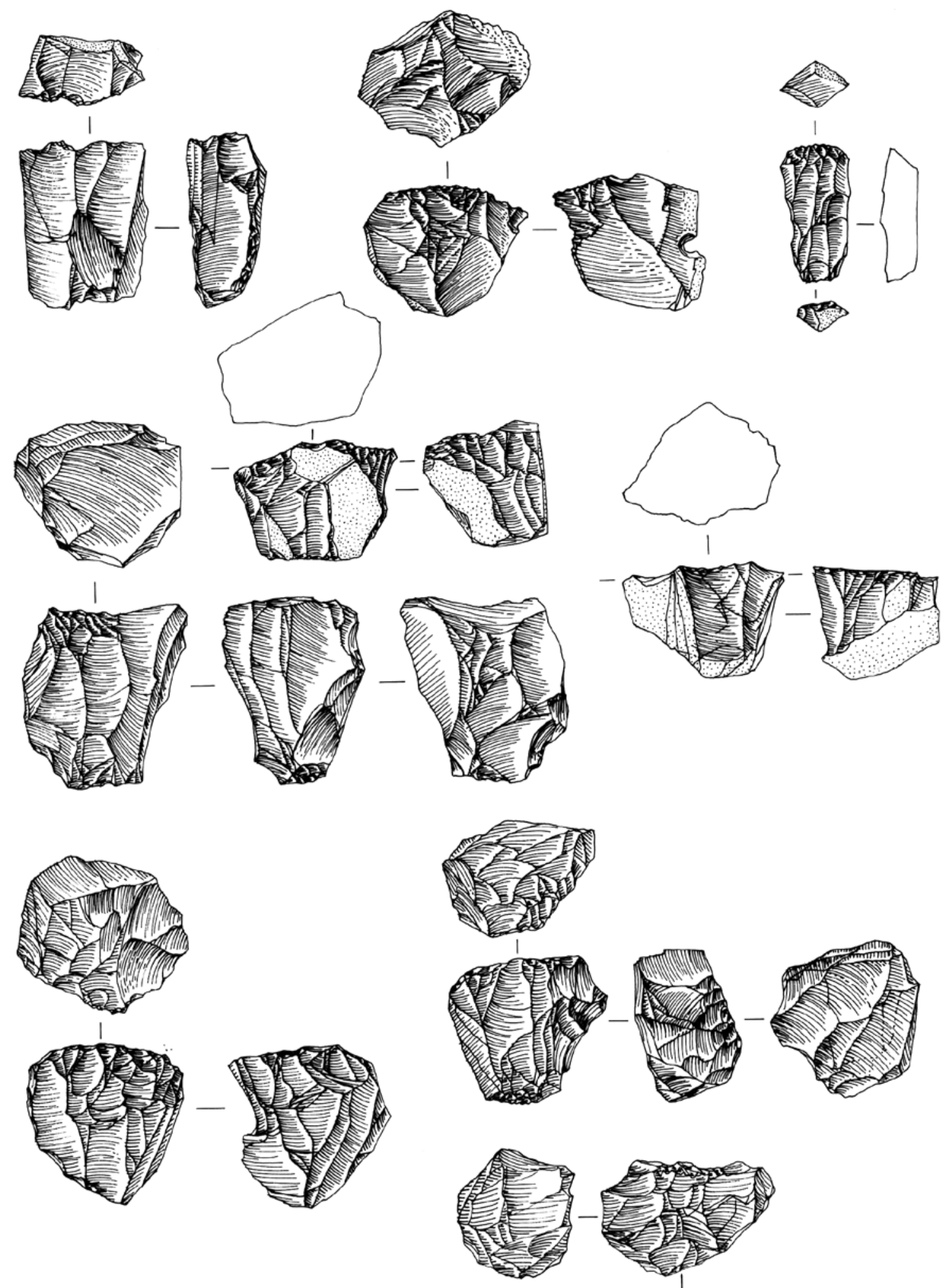

Fig. 19. Industria lítica N3 del Carabión: Núcleos / Lithic assemblage from Carabión N3: Cores.

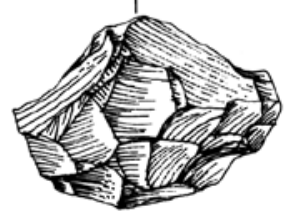



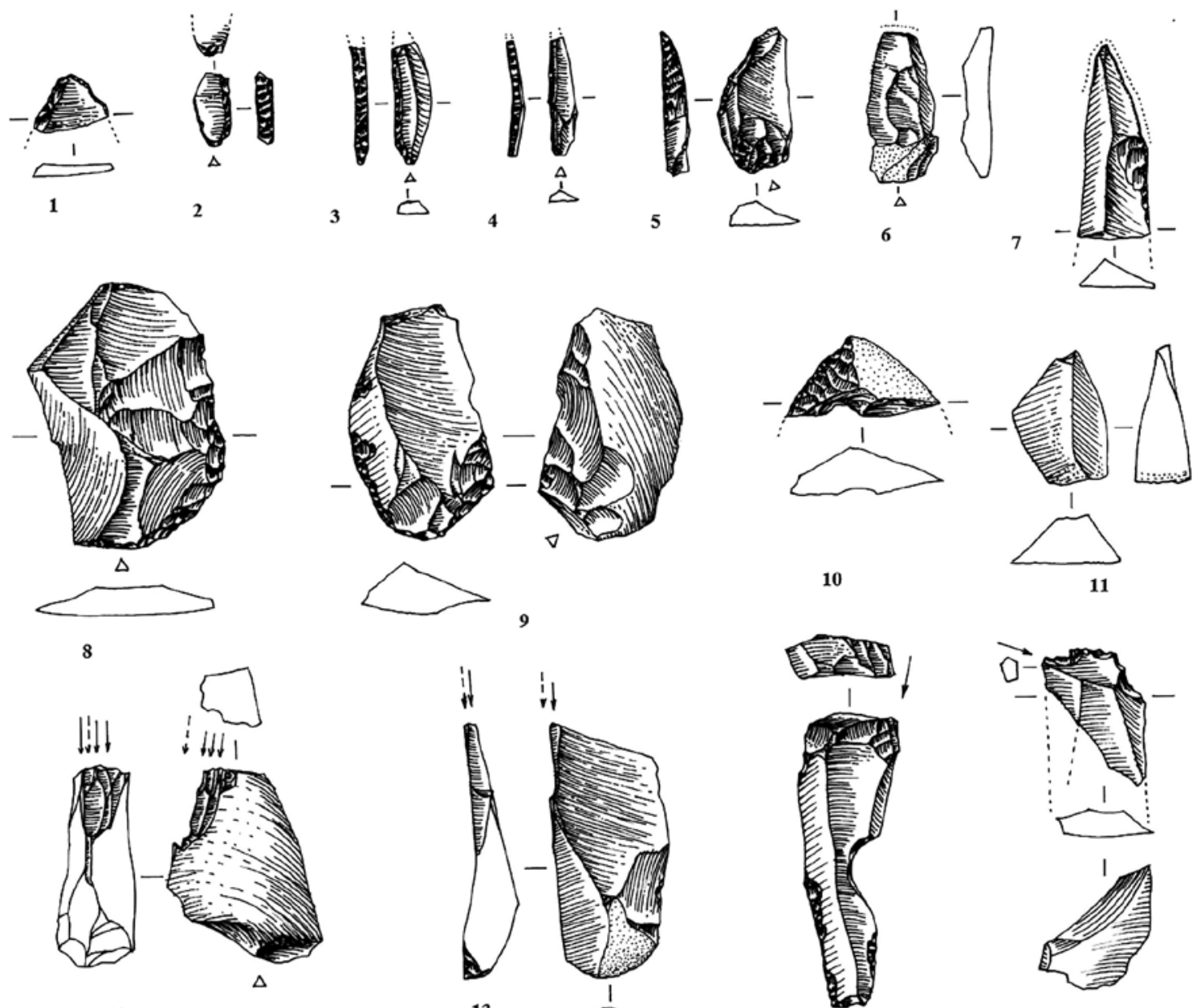

10
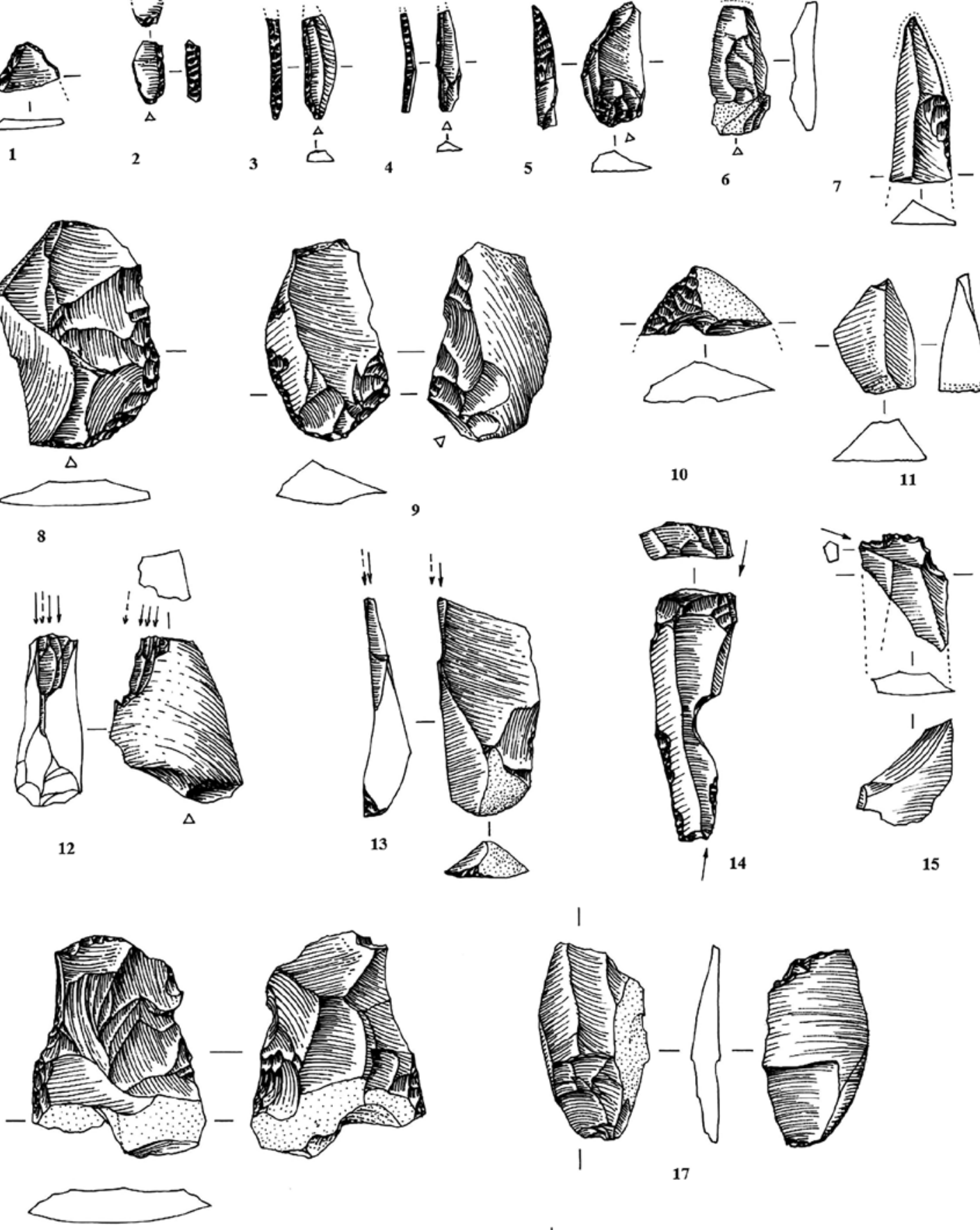

16

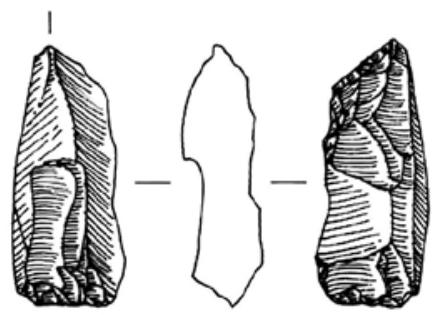

18

Fig. 20. Industria lítica retocada N3 del Carabión: Retoque simple (1, 8); Laminillas dorso (2, 3, 4); Punta aziliense (5); Buriles (10,11, 12); Raedera (7); Astillados $(6,14,15)$ / Retouched lithic assemblage from Carabión N3: simple retouch (1, 8); backed bladelets (2, 3, 4); Azilian point (5); burins (10, 11, 12); sidescrapers (7); splintered pieces $(14,15)$. 

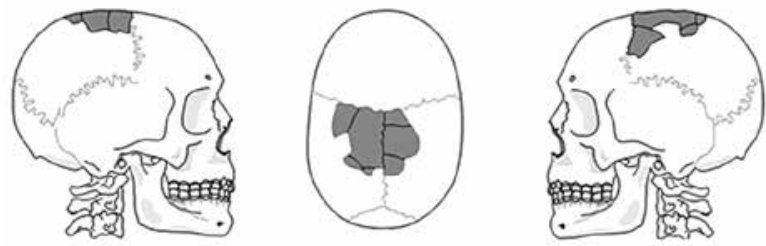

Fig. 21. Representación esquemática de los huesos conservados (Etxeberría) / Schematic representation of the preserved bones (Etxeberría).

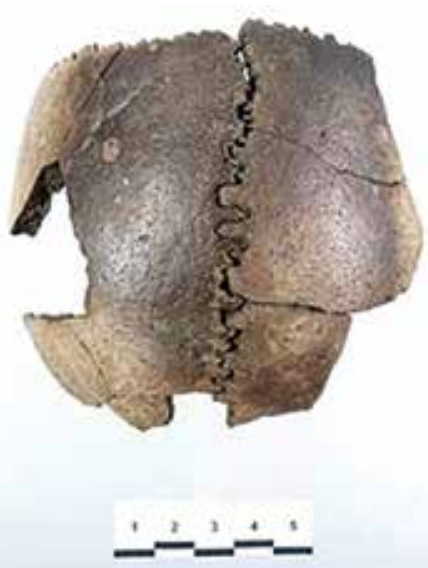

Fig. 22. Parte externa de los huesos de la región parietal / External face of the bones in the parietal region.

\section{DISCUSIÓN Y CONCLUSIONES}

La información expuesta sobre los resultados obtenidos en la intervención arqueológica efectuada en el abrigo del Carabión, nos lleva a valorar la secuencia ocupacional del yacimiento y los cambios que se observan en aspectos medioambientales, económicos y culturales.

1. Sobre los cambios ambientales se percibe en la secuencia estratigráfica de base a techo, un nivel (N4), que responde a la etapa de formación de la cavidad, estéril en restos arqueológicos. Sobre éste se asienta el primer nivel con evidencias de ocupación humana (N3). Las condiciones bioclimáticas indican procesos de bajas temperaturas final del Dryas III, atribución cultural Aziliense. Sobre este se asienta el N2, en el que se han podido constatar variaciones climáticas que suceden en el Holoceno. Un estrato compuesto de barros de ladera estéril en restos arqueológicos, nos informa del abandono de la cavidad y tal vez, del arrastre de parte del yacimiento. Este lapso se produce entre 10,3 ka BP y 7,8 ka BP. A partir de aquí las condiciones climáticas cambian, la cavidad vuelve a ser ocupada, dando lugar a la formación del paquete de conchero (N1). Tanto las fechas como la información de sedimentos y polen nos indican que se ha formado en un momento pleno del Holoceno entre el VIII y VI milenios BP, (sin calibrar), en el Boreal y Atlántico. En este momento el paisaje que rodea el yacimiento tuvo que verse afectado por la transgresión Flandriense (6.500 BP), por la proximidad a la ría y marisma.
2. El hiato ocupacional que se produce en el Carabión entre 10,31 y 7,8 Ka BP coincide con vacíos ocupacionales que se registran en la región cantábrica, entre el 10,1 y 9,6 ka BP). Este apagón, denominado "agujeros negros" (Estévez, 2002) analizado por Estévez y Gassiot (2002) se atribuye a pulsiones frías que se producen en el Holoceno. De los yacimientos datados, 12 tienen fechas que se sitúan antes y después del agujero (aunque no todas se consideran válidas): Arenaza (10,3-9,6 ka BP) representa el agujero menor, Berroberría (10,16-8,86 ka BP), Ekain (12,05-9,54 ka BP), La Riera (10,34-9,09 ka BP), Azules (10,33-9,54 ka $B P)$, El Mirón (10,25-9,55 ka BP), Morín (16-9 ka BP), Santimamiñe (>16-9,43 ka BP), Urtiaga $(10,28-8,7$ ka BP), Urratxa (10,25-9,55 ka BP).

El vacío poblacional se atribuye al impacto que los cambios ambientales pudieran tener sobre las poblaciones de cazadores-recolectores de la costa cantábrica a comienzos del Holoceno. Los cambios ambientales afectarían a la población de ciervos que por su tamaño, necesidades alimenticias y etología, sería la más sensible. Los valles abrigados de la costa pudieran servir de trampa mortal para los rebaños de ungulados. Bastaría una secuencia de algunos inviernos especialmente húmedos para acabar con la posibilidad de mantener una economía basada en la caza especializada del ciervo, que era la tendencia más marcada en este espacio (ESTÉVEZ Y GASSIOT, 2002).

El segundo agujero, tendría su origen en el evento 8200 cal. BP uno de los momentos de variabilidad climática más característicos del Holoceno, (8400-8000 cal. BP) (Bond et al., 1997; Barber et al., 1999; Dean et al., 2002; Heiri et al., 2004).

En la región cantábrica este segundo agujero se ha identificado entre $(8,195$ y 7,71 ka BP) y solo se cubría con las dataciones de Arangas $(8025 \pm 80 \mathrm{ka} \mathrm{BP})$ (ESTÉVEZ; GASSIOT, 2002). Nuevas dataciones obtenidas sobre yacimientos de la región cantábrica van rellenando este espacio: J3 (8.190 \pm 100 BP y $7780 \pm 130$ BP), Garma A $(8175 \pm 65,8165 \pm 65$ y $7985 \pm 65,7710 \pm 90$ y $7705 \pm 50 \mathrm{BP})$, Toralete $(7890 \pm 80 \mathrm{BP})$, Mazaculos II $(7840 \pm 40$ BP), Carabión $(7800 \pm 50$ BP). El más próximo al inicio es J3 y, al final, El Carabión (7,8 ka BP), El Águila $(7,705$ ka BP) y Kobeaga II (7,69 ka BP). Es probable que el abandono de algunas cavidades, como sucede en Carabión, El Perro o La Fragua, sea debido al empeoramiento de las condiciones de habitabilidad, motivado por esta pulsión fría que se manifestara en la cornisa cantábrica con abundante pluviosidad.

3. La etapa final parte superior del $N 1(-20 \mathrm{~cm})$, datada en 5,78 ka BP, es una fecha considerada en la región cantábrica como Neolítico inicial, en el que ya se han implantado algunos de los factores de la economía productiva. Sin embargo, en El Carabión y en algunos yacimientos de la cornisa cantábrica, no se evidencia la presencia de cereal, fauna doméstica y/o cerámica. Es

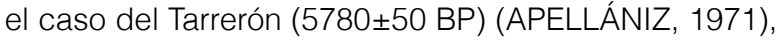


Cubío Redondo (5780 \pm 50 BP) (RUIZ COBO; SMITH, 2001), La Trecha (5600 \pm 310 BP) (GONZÁLEZ MORALES et al, 2002). No obstante en El Mirón se ha obtenido sobre cereal la fecha $(5550 \pm 40 \mathrm{BP})(\mathrm{PEN} \mathrm{N} A-\mathrm{CHOCA}-$ RRO et al, 2005:274).

En el País Vasco Atlántico, las dataciones obtenidas en Kobeaga Amk-s (6945 \pm 65 BP) y Marizulo IV (6820 \pm 150 BP) (FERNÁNDEZ ERASO et al., 2010); Marizulo I (6425 \pm 85 BP) (MARIEZCURRENA, 1990); Kobaederra II (6.360 \pm 70 BP) (ZAPATA et al, 997); Arenaza (6040 \pm 75 BP) (ARIAS; ALTUNA, 1999); MARIZULO (6035 \pm 100$)$ (ALDAY; MÚJICA, 1999); Herriko Barra (6010 \pm 90 BP y $5960 \pm 95$ BP) (IRIARTE et al, 2005), con presencia de cereal, fauna doméstica y/o cerámica evidencian la introducción de la economía productiva en el extremo oriental del Cantábrico, hacia el VI milenio cal. $\mathrm{BC}$, aunque, no en todos los sitios en los que se han documentado restos de un Neolítico Antiguo se detecta la presencia de animales domésticos (FERNÁNDEZ ERASO: 2004 y FERNÁNDEZ-ERASO et al, 2015).

2. Sobre la vegetación del entorno del yacimiento, los análisis de polen y carbones nos informan de cambios en la evolución del paisaje, con un componente arbóreo más denso en el nivel aziliense compuesto fundamentalmente por Pinus, Quercus-c y Corylus, con unas condiciones templadas y húmedas, que dieron lugar a la sustitución de los pinos por formaciones más templadas, datos que estarían en consonancia con lo observado en la región cantábrica por otros autores (FRANCO MÚGICA et al., 2001; GARCÍA ANTÓN et al., 2002; RUBIALES et al., 2008). En el nivel 2 queda patente la ausencia de elementos arbóreos y una escasa diversidad, este hecho es abrupto y puntual, y podría ser acorde con las características del evento 8200 cal BP. La vegetación en el nivel 1 evoluciona hacia condiciones más secas. Se observa el desarrollo de unos suelos relativamente secos, asociado al aumento de los Pastos, sobre suelos muy nitrificados, así como de taxones como Fabaceae y Apiaceae en cuyo seno se desarrollan elementos de interés alimenticio y de las Nitrófilas. Estos datos podrían ser interpretados como resultado de las primeras evidencias polínicas de antropización sobre el paisaje por parte de las comunidades mesolíticas, durante las cuales pudieron haber convivido las prácticas de caza y recolección con las de ganadería y agricultura, si bien estas últimas de forma puntual al igual que se ha documentado en otros trabajos del norte de la Península Ibérica (ZAPATA, 2002; IRIARTE et al., 2005; PEÑA-CHOCARRO et al., 2005a, 2005b). Por otro lado, en la madera quemada hay un predominio absoluto de Betula en el nivel aziliense y de Quercus en el nivel mesolítico. Este cambio coincide con la dinámica de vegetación Holocena: extensión progresiva del bosque caducifolio que desplaza a los taxones pioneros como el abedul o el pino. Este biotopo será intensamente explotado por las comunidades mesolíticos y de transición al Neolítico del nivel 1.
3. En el patrón económico se perciben diferencias entre ambos niveles de ocupación. En el N3, ocupación aziliense, la caza sería el principal recurso centralizado en el ciervo, pero con abundante presencia de cabra, especie de roquedo. La malacofauna es reducidísima y la pesca es también testimonial.

En el N1, ocupación mesolítica, se comprueba un patrón de captación de un amplio espectro de recursos, basado en la diversidad que ofrecen los diferentes biotopos surgidos de los nuevos paisajes propiciados por el cambio climático del Holoceno. Se constata una clara predilección por el ciervo siguiendo una tradición bien establecida durante el Paleolítico Superior en la región cantábrica. También hay otras especies de ungulados de tamaño más grande (uro) y más pequeño (cabra, rebeco, corzo y jabalí) que son objeto secundario de caza.

La casi total ausencia de restos de machos indica una estrategia cinegética centrada fundamentalmente en los rebaños de hembras y crías. Algunas de las presas abatidas son transportadas enteras al lugar de habitación pero otras fueron descuartizadas in situ y posteriormente transportadas con el abandono del espinazo y parte del armazón torácico formado por las costillas. El tipo de aprovechamiento es de carácter intensivo con rotura sistemática de las cañas de los huesos largos de cara a la obtención de la médula grasa tal como está registrado en otros yacimientos coetáneos de la Península Ibérica.

Este modelo del Carabión confirma una estrategia de caza que se produce en la región cantábrica, típica de los grupos del Paleolítico Superior y del Mesolítico, que evidencian una cierta especialización en la caza del ciervo en los asentamientos de valle, especializada en especies que vivían en rebaño, especialmente los grupos de ciervas y crías de poca edad, que son más vulnerables, y de la cabra montés en yacimientos situados en biotopos de roquedo. En definitiva la información obtenida a partir de la fauna en este yacimiento supone una aportación significativa a las estrategias de subsistencia de los últimos cazadores-recolectores de la Región Cantábrica.

La malacofauna tiene un peso importante en la dieta con la explotación intensiva del caracol terrestre, frecuente en el entorno de la cavidad, y prioridad en especies marinas de estuario, arenas y fangos sobre las de acantilado.

La pesca también se ha basado en especies de estuario. No se han hallado útiles relacionados con esta actividad en ninguno de los niveles fértiles. Es destacable la ausencia del típico arpón plano en el nivel aziliense. Respecto del N1, también se echa en falta otro útil de pesca frecuente en la zona asturiense, el anzuelo biapuntado, fabricado en asta o hueso. En los yacimientos analizados en esta zona de Cantabria, no se ha recuperado este útil, salvo un anzuelo hallado en $\mathrm{Cu}$ Ilalvera, sin contexto mesolítico (González Sainz; Muñoz 
y Morlote, 1997:73- 100). La ausencia de este tipo de útiles en el registro arqueológico, puede ser debida a la deficiente conservación, porque se hubieran fabricado en materiales vulnerables como la madera. Otra posibilidad, que se apunta en el caso del Carabión, por la presencia de peces de tamaño muy pequeño y, por tanto sin interés bromatológico, pudiera ser la utilización de trampas y nasas construidas con materia vegetal.

La recolección de productos vegetales, que suele tener un peso importante en la dieta de los cazadores-recolectores es difícil de recuperar en el registro arqueológico, ya que son productos perecederos. Solamente se ha podido documentar la recolección de avellanas.

El patrón económico que emerge, indica la prioridad en la explotación intensiva de los recursos inmediatos al hábitat y, pudiera indicar también, un aspecto en el patrón de poblamiento con tendencia hacia una cierta sedentarización.

4. En la industria lítica se observan claras diferencias entre el nivel aziliense y el nivel mesolítico.

En el nivel aziliense la industria lítica se ha elaborado de forma mayoritaria en sílex, con preferencia de sílex alóctonos de buena calidad. Aunque la colección es pequeña se observa en los soportes un índice laminar muy alto $(54,71 \%)$. La industria retocada es porcentualmente numerosa dentro del registro lítico $(11,14 \%)$. En la tipología, un rasgo que la diferencia de los conjuntos aziliense de la región cantábrica, son los índices bastante equilibrados entre raspadores y buriles y la ausencia de microlitos geométricos.

Próximos al Carabión se encuentran los yacimientos del área de Santoña el abrigo de la Peña del Perro y La Fragua, destacando la primera con una colección bastante similar aunque más rica. En áreas próximas hay otros yacimientos importantes como el Valle y las cuevas del Piélago, con importantes colecciones de microlitos geométricos, con colecciones muy diferentes a las que nos ocupan.

En el nivel mesolítico se percibe un claro descenso y simplificación de la industria lítica, lo que es común en los yacimientos mesolíticos de la cornisa cantábrica. De forma absoluta la materia prima es el sílex, pero en este caso hay un predominio de los tipos locales, próximos a la cavidad. El conjunto recuperado es reducido, con predominio del soporte sobre lascas, sin embargo, se observa un alto índice laminar en las tallas de base del nivel del conchero. El porcentaje de útiles es del 10,56\%. Se dispone de escasos datos de colecciones en Cantabria, los índices en colecciones superiores a 20 piezas, oscilan entre los obtenidos en La Garma Q (75 útiles: 5,37\%) y el Cubío Redondo (22 útiles: $10,38 \%$ ). El resto de las colecciones son muy reducidas.

El microlito geométrico recuperado en el Carabión, un segmento de círculo con talla doble bisel, en una cronología (4710-4490 cal BC), corresponde a un momento cultural atribuido al Neolítico inicial. La técnica del doble bisel aparece en yacimientos de la región cantábrica en contextos del VI milenio cal. BC.

En el País Vasco, en Pareko Landa (Bizkaia), se documenta esta técnica en la parte superior del nivel Is-Smk, datado (5790-5333 cal BC), ya en contacto con el nivel superior Sn (atribuido al Neolítico) (López Quintana 2005: 436). En Linatzeta (Guipuzcoa), en el hogar del nivel III, datado en (5210-4940 cal BC) se recupera un segmento de círculo con retoque doble bisel (Tapia et al. 2008:124).

En Asturias: La cueva de Los Canes (Arangas), en contextos mesolíticos funerarios datados entre el VI y el $\mathrm{V}$ milenio cal $\mathrm{BC}$, se ha hallado un segmento de círculo y tres triángulos con retoque doble bisel, con evidencia de interacción con sociedades neolíticas - presencia de cerámica-, pero sin presencia de economía productora (Arias y Fano, 2009:84). En el Mazo (Andrín-Llanes) (GUTIÉRREZ ZUGASTI et al, 2014) se ha recuperado un segmento de círculo y dos triángulos con retoque en doble bisel.

En Cantabria centro-oriental la talla en doble bisel se encuentra en el Cubío Redondo (un yacimiento de montaña) y en el Carabión (situado en la llanura litoral), ambos situados en fechas del V milenio cal BC, dentro de una cronología ya neolítica, sin evidencias de economía productora y, el hallado en el nivel 1 del abrigo de Barcenilla (Ibiden), se sitúa en un momento avanzado del Neolítico.

Una cuestión sobre los microlitos geométricos es la función de "fósil director", para caracterizar una etapa del Mesolítico en la región cantábrica que lo diferencia del Mesolítico occidental asturiense. El estudio efectuado por Arias y Fano en el marco de la región cantábrica, sobre el índice de microlitos geométricos en depósitos con un número de material retocado superior a 20 piezas, los yacimientos mesolíticos de La Garma A/Q, presentan un índice de 2,1 (sobre 47 piezas retocadas), Cubío Redondo, 4,8 (sobre 21 piezas retocadas). Los índices de los depósitos mesolíticos en la región cantábrica están entre 0,9 de Los Canes (Asturias) a 15, 8 en el mismo yacimiento y 22,7 en Kobeaga (País Vasco). Vemos que los índices de La Garma A y Cubío Redondo quedan muy debajo de estos porcentajes.

Concluyendo, la cronología de los microlitos con retoque doble bisel es compleja, no obstante es importante, no solo por el uso como discutible "fósil director", sino también por la aplicación de esta técnica que se ha considerado un indicio de transferencia tecnológica entre poblaciones de cazadores-recolectores y agricultores (Arias, 2007; Marchand, 2007; Guilaine et al, 2007:315, en (Arias y Fano, 2009:85).

5. El depósito funerario hallado en el Carabión, compuesto por seis fragmentos óseos correspondientes al cráneo de un individuo joven, por su cronología $(\mathrm{V}$ milenio cal $\mathrm{BC})$, debe situarse en un momento del 
Neolítico inicial, en el que perdura la practica funeraria de inhumación en cuevas. Se trata de un depósito aislado. En el $\mathrm{V}$ milenio cal BC, la información disponible se limita a los escasos datos proporcionados por cuatro cavidades en las que se han recuperado restos humanos datados en esta época: Los Canes (Asturias), Lumentxa (País Vasco), El Portillo del Arenal (Cantabria) (Arias, 2012) y este recuperado en el Carabión en Cantabria

A modo de conclusión final, el objetivo de esta publicación es dar a conocer un nuevo asentamiento en la región cantábrica con un depósito de ocupación que aborda el tránsito entre el Tardiglaciar y el Holoceno medio. La información que aportan los estudios de los materiales arqueológicos recuperados contribuye a ampliar la información sobre los cambios ambientales así como las adaptaciones y cambios socio-económicos que se producen en los últimos cazadores-recolectores en la región cantábrica.

\section{AGRADECIMIENTOS}

Queremos manifestar nuestro agradecimiento a la Consejería de Educación, Cultura y Deporte de Cantabria que ha subvencionado el proyecto. Agradecer también a los correctores del artículo sus sugerencias que han contribuido a mejorar la calidad del artículo.

\section{BIBLIOGRAFIA}

ALDAY RUIZ, A.

2009 El final del Mesolítico y los inicios del Neolítico en la Península Ibérica: cronología y fases. Munibe Antropologia-Arkeologia 60, 157-173.

ALDAY, A. y MÚGICA, J.A.

1999 Nuevos datos de cronología absoluta concerniente al Holoceno Medio en el área vasca, en El Mundo indígena. XXIV Congreso Nacional de Arqueología. 95-106. Instituto de Patrimonio Histórico. Murcia.

\section{APELLÁNIZ CASTROVIEJO, J.}

1971 El Mesolítico de la Cueva de Tarrerón y su datación por el C - 14. Munibe 23(1), 91-104.

ARIAS CABAL, P. y ALTUNA, J.

1999 Nuevas dataciones absolutas para el Neolítico de la Cueva de Arenaza (Bizkaia). Munibe Antropologia-Arkeologia 51, 161-171.

ARIAS, P. y FANO MARTÍNEZ, M.A.

2009 ¿Mesolítico geométrico o Mesolítico con geométricos? el caso de la región cantábrica, en UTRILLA MIRANDA M. \& MONTES RAMÍREZ, L. (eds.). El mesolítico geométrico en la Península Ibérica. 69-92. Zaragoza-Jaca. 2008. Monografías Arqueológicas Prehistoria 44.
ARIAS CABAL, P., GONZÁLEZ SAINZ, C., MOURE ROMANILLO, J.A. y ONTAÑÓN PEREDO, R.

2000 Estudio integral del Complejo Arqueológico de La Garma (Omoño, Ribamontán al Monte), en ONTAÑÓN PEREDO (ed.). Actuaciones arqueológicas en Cantabria 1984-199. 270-277.

\section{BARANDIARAN, I}

1990 Revisión estratigráfica de Berroberría: Datos en 1990. Veleia 7, 7-33.

BARANDIARÁN, I. y CAVA, A.

1986 Yacimiento de Portugain (Urbasa-Navarra). Informe preliminar de las campañas de 1984-1985. Trabajos de Arqueología de Navarra 5, 7-18.

BERGANZA, E. y ARRIBAS, J.L.

1994 El asentamiento paleolítico de Laminak II. (Berriatua, Bizcaya). Kobie 21,5-253.

BARBER, D.C., DYKE, A., HILLARIE-MARCEL, C., JENNINGS, A.E., ANDREWS, J.T., KERWIN, M.W., BILODEAU, G., MCNEELY, R., SOUTHON, J., MOREHEAD, M.D. y GAGNON, J.M.

1999 Forcing of the cold event of 8200 years ago by catastrophic drainage of Laurentide lakes. Nature 400, 344-348.

BOND, G., SHOWERS, W., CHESEBY, M., LOTTI, R., ALMASI, P., DEMENOCAL, P., PRIORE, P., CULLEN, H., HAJDAS, I. y BONANI, G.

1997 A pervasive millenial-scale cycle in North Atlantic Holocene and glacial climates. Science 278, 1257-1266.

\section{CASTAÑOS, P}

1980 La Macrofauna de la cueva de La Paloma, en HOYOS GOMEZ, M. y MARTINEZ NAVARRETE T. La cueva de La Paloma. Soto de Las Regueras (Asturias). 65-100. Madrid. Excavaciones arqueológicas en España 116.

CENDRERO, A., DÍAZ DE TERÁN, J.R., FLOR, E., FRANCÉS, E. y GONZÁLEZ LASTRA, J.R.

1986 Guía de la Naturaleza de Cantabria. Ed. Librería Estudio. Santander.

CLASON, A. T.

1972 Some remarks on the use and presentation of archaezoological data. Helinium, XII 12, 139-153.

\section{COÛTEAUX, M.}

1977 A propos de l'interprétation des analyses polliniques de sédiments minéraux, principalement archéologiques, en LAVILLE, H. y RENAULT-MISKOVSKY, J. (Eds.). Approche écologique de l'homme fossile. 259276. Supplémént du Bulletin de l'Association Française pour l'Etude du Quaternaire 47.

DEAN, W.E., FORESTER, R.M. y BRADBURY, J.P.

2002 Early Holocene change in atmospheric circulation in the Northern Great Plains: an upstream view of the $8.2 \mathrm{ka}$ cold event. Quaternary Science Reviews 21, 1763-1775. 
DIEZ CASTILLO, A

2010 Nuevas tecnologías y viejas piedras: un repaso al megalitismo en Cantabria. Illunzar, 7-35.

DRAK, L. y GARRALDA, M ${ }^{2} \mathrm{D}$

2009 Restos humanos mesolíticos en la Cordillera Cantábrica (Note de España). Estudios de Antropología XIV-1, 261-282. México.

\section{ESTÉVEZ ESCALERA, J. y GASSIOT BALLBÈ, E.}

2002 El cambio en sociedades cazadoras litorales: tres casos comparativos. Revista Atlántica Mediterránea de Prehistoria y Arqueología Social 5, 43-85.

\section{ETXEBERRÍA, F.}

1994 Aspectos macroscópicos del hueso sometido al fuego Revisión de las cremaciones descritas en el País Vasco desde la arqueología. Munibe Antropologia-Arkeologia 46, 111-116.

FANO, M.A.

2007 Un nuevo tiempo el Mesolítico en la región cantábrica, en FANO MARTINEZ, M.A. (Ed.). Las sociedades del Paleolítico en la región Cantábrica. 337-401. Kobie Anexo 8.

\section{FERNÁNDEZ-ERASO, J.}

2004 El Neolítico Inicial en el País Vasco Meridional. Datos recientes. Kobie. Anejo 6, 181-190.

FERNÁNDEZ ERASO, J., MUJIKA ALUSTIZA, J.A. y PEÑALVER, IRIBARREN, $X$.

2010 Hábitat y mundo funerario en la prehistoria reciente del País Vasco: nuevas evidencias. Munibe. Suplemento 32, 250-269.

FERNÁNDEZ ERASO, J., MUJIKA ALUSTIZA, J.A., ZAPATA-PEÑA, L., IRIARTE-CHIAPUSO, M.J., POLO-DIAZ, A., CASTAÑOS, P., TARRIÑO-VINAGRE, A., CARDOSO, S., SESMA-SESMA, J. \& GARCÍA-GAZOLAZ, J.

2015 Beginnings, settlement and consolidation of the production economy in the Basque region. Quaternary International 364, 162-171.

FRANCO MÚGICA, F., GARCÍA ANTÓN, M. \& MALDONADO, J.

2001 The Holocene history oí Pinus forests in the Spanish Northern Meseta. The Holocene 11, 343-358

GARCÍA ANTÓN, M., MALDONADO RUIZ, J., MORLA JUARISTI, C. \& H. SAINZ OLLERO

2002 Fitogeografía histórica de la península Ibérica, en PINEDA, F.D., MIGUEL, J.M., CASADO, M.A. \& MONTALVO, J. La diversidad Biológica en España. CYTED.

\section{GONZÁLEZ MORALES, M.R.}

2000 La Prehistoria de las Marismas: Excavaciones en la Cueva de La Fragua (Santoña). Campañas de 19901996, en ONTAÑONN, R. (Ed.). Actuaciones arqueológicas en Cantabria, 1984-1999. 177-179. Gobierno de Cantabria. Santander.
GONZÁLEZ MORALES, M.R. y DÍAZ CASADO, Y.

2000 La Prehistoria de las Marismas: excavaciones arqueológicas en los abrigos de la Peña del Perro (Santoña). Actuaciones arqueológicas en Cantabria 1984-1999, 93-96.

GONZÁLEZ MORALES, M.R., DÍAZ CASADO, y YUDEGO ARCE, C.

2002 Excavaciones en la Cueva de la Trecha de la Fuente La Corredora (Islares, Castro Urdiales), en ONTAÑÓN PEREDO, R. (Ed.). Actuaciones Arqueológicas en Cantabria 1987-1999 Arqueología de Gestión. 49-53. Gobierno de Cantabria. Consejería de Cultura Turismo y Deporte Cantabria. Santander.

GONZÁLEZ SAINZ, C., MUÑOZ FERNÁNDEZ, E. y MORLOTE EXPÓSITO, J.M

1997 De nuevo en la Cullalvera (Ramales, Cantabria). Una revisión de su conjunto rupestre paleolítico. Veleia 14 73-199.

GUTIÉRREZ ZUGASTI, F.I.

2006 Análisis arqueomalacológico de la Cueva de La Fragua (Santoña, Cantabria, España), en FERREIRA BI$\mathrm{CHO}$, Nuno (Ed.). Animais na Pré-história e Arqueologia da Península Ibérica. Actas do IV Congresso de Arqueologia Peninsular (Faro, 14 a 19 de Setembro de 2004). 197-210. Universidade do Algarve. Faro.

HEIRI, O., TINNER, W. y LOTTER, A.F.

2004 Evidence for cooler European summers during periods of changing meltwater flux to the North Atlantic. Proceedings of the National Academy of Sciences of the United States of America 101(43), 15285-15288.

IRIARTE, M.J., ARRIZABALAGA, A., ETXEBARRÍA, F. y HERRASTI, L.

2005 La inhumación humana de J3 (Hondarribia, Guipuzcoa), en ARIAS, P., ONTAÑÓN, R. y GARCÍA-MONCÓ, C. (Eds.). III Congreso del Neolítico en la Península Ibérica. 607-613. Monografías del Instituto Internacional de Investigaciones Prehistóricas Servicio de Publicaciones. Universidad de Cantabria. Santander.

IRIARTE, M.J., MUJIKA, J. \& TARRIÑO, A.

2005 Herriko Barra (Zarautz-Gipuzkoa): caracterisation industrielle et economique des premiers groupes de producteurs sur le littoral Basque, in Actas del Colloque Unite et diversite des processus de neolithisation sur la façade atlantique de l'Europe. 127-136. Bulletin de la Societe Prehistorique Francçaise XXXVI.

LAPLACE, G.

1971 De l'application des coordonnées à la fouille stratigraphique. Munibe 23(2/3), 223-236.

LAPLACE, G. \& MÉROC, L.

1954 Application des coordonnées cartésiennes à la fouille d'un gisement. Bulletin de la Société Préhistorique Française LI, 58-66.

1956 Técnica de exploración arqueológica. Empleo de las coordenadas cartesianas según G.Laplace y L.Méroc. Escuela Nacional de Antropología e Historia, $2^{a}$ época. 18-21. México. 
MARIEZKURRENA, $\mathrm{K}$.

1990 Caza y domesticación durante el Neolítico y la Edad de los Metales en el País Vasco. Munibe Antropologia-Arkeología 42, 241-252.

\section{MARIEZKURRENA, K. y ALTUNA, J.}

1989 Análisis arqueozoológico de los macromamíferos del yacimiento de Zatoya. Trabajos de Arqueología Navarra 8, 237-266.

1995 Fauna de mamíferos del yacimiento costero de Herriko Barra (Zarautz, País Vasco". Munibe Antropologia-Arkeologia 47, 23-32.

MARÍN ARROYO, A. B.

2004b Análisis arquezoológico, tafonómico y espacial de los restos de mamíferos de la Cueva de la Fragua. Munibe Antropologia-Arkeologia 56, 19-44.

MORA TORCAL, R., MARTÍNEZ MORENO, J., RODA GILABERT, X., ROY SUNYER, M. \& VEGA BOLIVAR, S.

2014 Métodos de excavación: del trabajo de campo a la interpretación arqueológica. Treballs d'Arqueología 20, 7-20.

MUÑOZ FERNÁNDEZ, E.

1997 Los concheros Holocénicos en Cantabria. Trabajo de investigación de Tercer Ciclo. Universidad de Cantabria. Inédita.

MUÑOZ, M. y BERGANZA, E.

1997 El yacimiento de la cueva de Urratxa III (Orozco, Bizcaia). Universidad de Deusto. Bilbao.

PEÑA CHOCARRO, L., ZAPATA, L., IRIARTE, M.J., GONZÁLEZ MORALES, M. \& STRAUS, L.G.

2005 The oldest agriculture in northern Atlantic Spain: new evidence from El Mirón Cave (Ramales de la Victoria, Cantabria). Journal of Archaeological Science, 1-9.

\section{PÉREZ BARTOLOMÉ, M.}

2014 El Abrigo del Carabión: Recuperación de materiales, consolidación y conservación de la estratigrafía (San Mamés de Aras - Voto), en ONTAÑÓN PEREDO, R. y SANZ PALOMERA, G. (eds.). Actuaciones Arqueológicas en Cantabria. Arqueología de Gestión 2004-2011. 373-380. Consejería de educación, Cultura y Deporte.

2016 Proyecto de dataciones C14 AMS en los valles del Asón y Agüera (2006), en ONTAÑÓN PEREDO, R. y SANZ PALOMERA, G. Actuaciones Arqueológicas en Cantabria. Arqueología de Investigación 2004-2011. 121-126. Consejería de educación, Cultura y Deporte.

\section{ROSELLÓ E. \& BRINKHUIZEN, D.}

1994 Laminak II/ Spain: Alternative taxonomies as approaches to the interpretation of a fish fauna. Offa 51, 401-409.

RUIZ COBO, J., MUÑOZ FERNÁNDEZ, E., BERMEJO CASTRILLO, A., GARCÍA GÓMEZ, P., PÉREZ BARTOLOMÉ. M. y SMITH, P.

2009 La Prehistoria del Bajo Asón. B.A.R International Series 1936. Oxford
RUIZ COBO Y SMITH, P.

2001 El yacimiento del Cubío Redondo (Matienzo, Ruesga): Una estación mesolítica de montaña en Cantabria. Munibe Antropologia-Arkeologia 53, 31-55.

\section{SÁENZ DE BURUAGA, A.}

2015 Recorrido y reflexiones en torno al pensamiento analítico de Georges Laplace: Movimiento, interdependencia y arquetipos en la construcción de una Arqueología científica, en CALVO, A., SÁNCHEZ, A., GARCÍA-ROJAS, M. y ALONSO-EGUíLUZ, M. Seis décadas de tipología analítica. Actas en homenaje a Georges Laplace 13,14 y15 de noviembre de 2012. Vitoria-Gasteiz.

\section{SONNEVILLE BORDES, D. y PERROT, L.}

1954 Lexique typologique du Paléeolithique superieurr. Boulletin de la Société préhistorique de France 51(7), 327-335.

\section{SOTO BARREIROS, M.J.}

2003 Cronología Radiométrica, Ecología y Clima del Paleolítico Cantábrico. Monografías 19 Museo Nacional y Centro de Investigación de Altamira.

UZQUIANO, P.

1992a Recherches anthracologiques dans le secteur Pyréneo-cantabrique (Pays Basque, Cantabria et Asturias): Environnements et relations homme-milieu au Pléistocène supérieur et début de l'Holocène. Thèse Biologie des Organismes et Populations, Environnements et Archéologie. U.S.T.L. Montpellier II.

1992b The Late-glacial/Postglacial transition in the Cantabrian Cordillera (Asturias and Cantabria, Spain) based on charcoal analysis. Palaios 7(5), 540-547. SEMP (Society for Sedimentary Geology). L.A. California.

1995 L'évolution de la végétation à l'Holocène initial dans le Nord de l'Espagne à partir de l'étude anthracologique de trois sites archéologiques. Quaternaire 6(2), 77-83.

1998 La végétation cantabrique de 13000 à 9000 BP d'après l'analyse anthracologique. Habitats et ramassages de bois dans un milieu changeant. Proceedings of the XIIIth U.I.S.P.P. Congress, Forli, Italia Septiembre 1996.

ZAPATA, L.

2002 Análisis de los macrorrestos vegetales de Kobeaga II: La explotación del bosque. Ilunzar.

ZAPATA, L., IBÁÑEZ, J.J. y GONZÁLEZ URQUIJO, J.E.

1997 El yacimiento de la cueva de Kobaederra (Orna, Kortezubi, Bizkaia). Resultados preliminares de las campañas de excavación 1995-97. Munibe Antropologia-Arkeologia 49, 51-63.

WHEELER, A. \& JONES, A.K.G.

1989 Fishes. Cambridge University Press.

WENINGER, B., JORIS, O. \& DANZEGLOCKE, U.

2007 CalPal-2007 Cologne radiocarbon calibration \& palaeoclimate research package. Radiocarbon Laboratory, Cologne University. Cologne. 